Robbin, A. (1995). SIPP ACCESS, an information system for complex data: A case study in creating a collaboratory for the social sciences. Internet Research: Electronic Networking Applications and Policy, 5(2), 37-66. 


\title{
SIPPACCESS, an information system for complex data: a case study creating a collaboratory for the social sciences
}

\author{
A lice R obbin
}

\begin{abstract}
The author
Alice Robbin <arr@cunyvmsl.gc.cuny.edu> is Associate Professor in the Public Policy Program of the School of Public Affairs at Baruch College, New York City, New York, and Adjunct Professor in the PhD Sociology Program, Graduate Center/City University of New York. Previously, she was senior scientist at the University of Wisconsin-Madison, where she was a Co-director and Co-principal Investigator of the SIPP ACCESS project at the Institute for Research on Poverty.
\end{abstract}

\section{Abstract}

The "collaboratory" concept has recently entered the vernacular of the scientific community to reflect new modes of scientific communication, cooperation and collaboration made possible by information technology. The collaboratory represents a scientific research center "without walls" for accessing and sharing data, information, instrumentation and computational resources. The principal applications of the collaboratory concept have been in the physical and biological sciences, including space physics, oceanography and molecular biology. Discusses the attributes of the collaboratory, and applies the concept developed by computer and physical scientists to the design and operation of the SIPPACCESS prototype information system for complex data to be used through the Internet by sociologists, demographers and economists. Examines obstacles to collaboratory development for the social sciences. Concludes that four major obstacles will inhibit the development of collaboratories in the social sciences.

Internet Research: Electronic Networking Applications and Policy Volume $5 \cdot$ Number $2 \cdot 1995 \cdot$ pp. 37-66

(c) MCB University Press · ISSN 1066-2243

\section{Introduction}

Computers and telecommunications have dramatically altered the conduct of science during the last two decades. R eflecting on these developments at a 1989 workshop that addressed the relationship between information technology[1] and scientific research, W illiam Wulf coined the metaphoric phrase "collaboratory" to represent new modes of communication, cooperation and collaboration ("c-cubed") that would improve the efficiency and effectiveness of the scientific enterprise. He wrote that a collaboratory represented a "center without walls, in which the nation's researchers can perform their research without regard to physical location - interacting with colleagues, accessing instrumentation, sharing the data and computational resources, [and] accessing information in digital libraries" (Wulf, 1989, cited by Wulf, 1993). M ore recently, he suggested that not only would scientific productivity be increased by leveraging technology, but technology also had the potential to "qualitatively change the kinds of questions we ask and, hence, what we know about nature" (Wulf, 1993, p. 854).

Wulf would agree that his was not a new conception of how computer and telecommunications technologies would modify scientific work[2]. The particular relevance of Wulf's collaboratory concept was, however, that it focussed the attention of science elites on the fact that scientific information infrastructure development was not principally a problem of technology which necessitated engineering solutions - problems to which the $\mathrm{H}$ igh Performance C omputing Act of 1991 was designed to respond (C ommittee on Physical, $M$ arketing and Engineering Sciences et al., 1992; N ational Research C ouncil, 1994a; U S C ongress, 1994)[3]. As the computer scientist Wulf himself noted, "T he bottleneck to the achievement of such a vision is not hardware" (1993, p. 854)[4].

Thanks go to an anonymous reviewer who made constructive observations about current trends in the electronic network environment. The SIPP AC CESS project was a truly collaborative venture and, as such, my colleagues $M$ artin D avid and T homas F lory at the $U$ niversity of $W$ isconsin- $M$ adison are (silent) co-authors of this article. 
D uring the 1980s and early 1990s, national policy and planning initiatives in biology, neuroscience, oceanography, and space physics began to articulate the critical importance of information and data as resources necessitating human structures to organize and manage them (e.g. G reenstadt, 1981; L ander et al., 1991; Cinkosky et al., 1991; N ational Research C ouncil, 1990, 1991a, 1991b, 1994b; Pechura and M artin, 1991)[5]. Reports on information technology and scientific research published by the U S Office of Technology A ssessment, prestigious scientific panels, and $\mathrm{N}$ ational Science Foundation-sponsored workshops, between 1989 and 1993, further reinforced Wulf's perspective (e.g. F rench et al., 1990; $\mathrm{N}$ ational Academy of Sciences et al., 1989; $N$ ational Research Council, 1993; Scheuermann et al., 1989; Silberschatz et al., 1990; U S C ongress, 1988; U S C ongress, 1991b). T hese reports underscored the scientific community's increasing attention to the need for systematic organization, management and retrieval of data and information, and the management of instrumentation.

An important perspective on human resources was being developed, as implied by the words "organization" and "management". For example, molecular biologists commented that:

Effectively storing data and its associated information is likely to be among the major challenges confronting biologists over the coming decades.... $M$ aking all this information easily accessible to distributed users while effectively dealing with errors, conflicts, and updates presents a challenging research problem of the utmost urgency (L ander et al., 1991, p. 34).

A new emphasis on human capital placed the importance squarely on the behavioral, the cognitive (in terms of information processing and retrieval capabilities of the scientist) and the communicative (the interpersonal, group, political and economic structures and processes required for organizing the scientific community, information and data) [6]. N euroscientists wrote that:

The scientific enterprise is composed of men and women who generate ideas, design ways to test those ideas, collect data, and communicate the ideas and data in a variety of ways. The communication of ideas and results is as important to the growth of knowledge as the data themselves....
O ne of the major goals of computer network development is to create a communication environment that is as free of barriers as possible - an environment that can support the rapid communication of ideas and images at every stage of experimentation and discovery (Pechura and $\mathrm{M}$ artin, 1991, p. 84).

The discussion of collaboratory developments, as recorded in the authoritative reports issued by the $\mathrm{N}$ ational Academy of Sciences (N AS) and $\mathrm{N}$ ational Research Council (N RC) panels, does, however, leave the unfortunate impression that information infrastructure building activities occurred only in the physical and biological sciences during the 1980s. This article is, however, designed to rectify that impression by discussing an example of information infrastructure development in the social sciences.

The first section describes the collaboratory concept and capabilities that were identified in the N RC reports and other documents on which the NAS and NRC scientific panels relied to develop their recommendations for maximizing information technology to enhance the scientific enterprise. Although there are critical technical and engineering attributes that must be in place for a collaboratory to exist, such as the physical architecture of an information infrastructure (see M cC lure et al., 1994; $\mathrm{N}$ ational Research C ouncil, 1994a), this discussion emphasizes a particular model of an electronic community system that influenced the final recommendations for collaboratory development by the various scientific panels. Bruce Schatz's vision of an information system, which was designed to create an electronic community of molecular biologists who study various aspects of the nematode worm Caenorhabditis elegans, appears to have been instrumental in formalizing the attributes of a collaboratory. Schatz wrote that "an electronic community system encodes and manipulates the range of knowledge and values necessary to function effectively in a community or organization" (1992, pp. 87-8). T he encoded knowledge represents institutionalized organizational memory (see also Simon, 1991). T he task of information infrastructure development is, therefore, to create an integrated environment of tools and technologies that permanently records socially-generated, historical and 
current, formal and informal knowledge shared by a scientific community.

The second section presents a case study of SIPP ACCESS, a project to develop a prototype of an information system for complex data used by social scientists and policy analysts using the Internet, which began in late 1984 and was completed in D ecember 1991 at the $U$ niversity of $W$ isconsin-M adison ( $D$ avid and R obbin, 1992). T he discussion emphasizes: the theoretical basis on which the different components of the information system rested; the system's environment, functionality and structures; and the activities designed to create an integrated knowledge base of an electronic community as represented by the information system. Selective administrative data collected by the SIPP ACCESS project illustrate the ways in which information technology was applied to achieve improvements in efficiency and effectiveness. It is important to note at the outset that SIPP AC CESS was created at the beginning of a dynamic and unstable period of considerable technological change and standards development in the environment, including applications software, computer architecture, computational capacity and telecommunications. C onsequently, some of the enabling information technology that is currently in widespread use either had yet to be "invented" or was in the early stages of development during the principal years of SIPP ACCESS operation and therefore "matured", and became widely accessible and affordable, only toward the end of the project (and thus too late to be incorporated in the information system)[7].

The third and final section of the article discusses some of the obstacles and problem areas related to the collaboratory concept and effective use of information technology identified by the N RC panels in terms of their applicability to the social sciences. We rely on empirical data collected by the SIPP ACCESS project, as well as our observations of social scientists conducting work in the electronic network, that both support and augment the discussion of the problem areas raised by the N RC reports. We discuss:

- the conceptual/technical problems of creating integrated information systems for heterogeneous scientific databases;

- cognitive and other attributes of users;
- collaboration between computer scientists and social scientists; and

- cumulative advantage of institutions.

\section{Part one: the collaboratory concept and capabilities}

The scientific research enterprise includes the major activities of data collection and analysis, communication and collaboration among scientists, and information storage and retrieval ( $N$ ational A cademy of Sciences et al., 1989, p. 2). According to the $\mathrm{N}$ ational $\mathrm{C}$ ollaboratories report, eight mutually reinforcing changes have affected the conduct of science and have promoted an interest in collaboration ( $\mathrm{N}$ ational Research Council, 1993, pp. 5-6, 8).

These eight factors, shown in italics, are: the increasingly complex phenomena and problems selected for study, made possible by developments in instrumentation and facilities that provide the capability for making more precise mea surements but which are increasingly expensive. $T$ he nature of the scientific activity has resulted in an enormous growth in the volume of data and information that must be stored, accessed, analyzed and reported, which requires advanced information technology to manage the complexity of the phenomena under investigation ( e.g. to collect, process, analyzeand share the massive amounts of data being generated from observations and experiments), and highly trained and specialized personnel to perform the tasks in structurally more differentiated work/production units (see also U S C ongress, 1991b; US N ational Institutes of $\mathrm{H}$ ealth, 1993). T here has also been an increased interest in interdisciplinary research due to the recognition that " many pressing scientific problems transcend the boundaries of individual disciplines" (N ational Research C ouncil, 1993, p. 7) and require "the meshing of different specializations to advance a research area" (U S C ongress, 1991b, p. 35). F inally, fueling the interest in modifying organizational arrangements is the more restricted funding environment to support the scientific enterprise. Collaboration is thus viewed instrumentally as a way to address both complexity and the "stretching and leveraging of available dollars" ( $\mathrm{N}$ ational Research Council, 1993, p. 7).

The $\mathrm{N}$ ational $\mathrm{C}$ ollaboratories report ( $\mathrm{N}$ ational Research C ouncil, 1993) provides both abstract and operational definitions of a collaboratory 
for scientific research. Abstractly, the collaboratory is Wulf's "center without walls" (Wulf, 1989, cited in Wulf, 1993). L ess abstractly, a collaboratory is an integrated environment of knowledge-generating tools and technologies designed to enhance scientific activity wherever it may take place. "K nowledge" is more preciseIy defined by Schatz as comprised of:

both formal data and literature and informal results and news [that are manipulated by the scientist]. M anipulation includes... browsing through the available knowledge and recording and sharing interrelationships between the items [in a] software environment to manipulate this knowledge... [by] people with common interests and shared values (Schatz, 1992, pp. 87-8).

Translated into operational terms, the collaboratory concept is an information infrastructure that " provides a technological base specifically created to support interaction among scientists, instruments, and data networked to facilitate research conducted independent of distance" (N ational Research C ouncil, 1993, p. 7). C ollegial relationships are defined by area of specialization and not geographic location ( $N$ ational A cademy of Sciences et al., 1989, p. 20; see also L ederberg, 1978). T he physical components of the information system are independent of the geographic location of the scientist.

Five criteria for this technological base must be satisfied: interoperability, transparency, customizability, integrity, and extensibility (N ational Research C ouncil, 1993, pp. 28-9)[8]. A complete environment for collaborative scientific activity comprises:

- a distributed computer system;

- networked laboratory instruments and datagathering platforms;

- tools to enable a variety of collaborative activities;

- financial and human resources for maintaining, evolving, coordinating, and assisting in the use of computer-based facilities;

- digital archives and libraries that include tools for organizing, describing and managing data, including images, to enable largescale sharing of data; and

- digital libraries which include tools for organizing, describing and managing the information derived from the analysis of the shared data.
To make these activities possible, a collaboratory must support four basic capabilities:

(1) D ata and information sharing: scientists who work on the same project should be able to obtain data and information quickly and easily from within and across databases.

(2) Software sharing: scientists should be able to share and exchange software conveniently for data analysis, visualization, modeling, information retrieval, etc.

(3) Controlling remote instruments: scientists should be able to control instruments (located in difficult-to-access regions on Earth or in space).

(4) Communicating with remote colleagues: scientists should be able to interact effectively with one another, despite being separated in space and/or time ( $\mathrm{N}$ ational Research Council, 1993, p. 56).

\section{Data and information sharing}

$D$ ata and information sharing require three essential, dynamic, and interconnected components:

(1) Electronic libraries contain published and unpublished data(bases), formal and informal literature and unpublished findings that contribute to the knowledge base (Schatz, (1992, p. 95) calls the latter "lore"), and analysis and other applications software.

(2) The collaboratory maintains accessible archives of data.

(3) The facility provides a comprehensive system of "metadata" and "finding aids" to support browsing, filtering, retrieval and sharing of data and information.

Without exception, all disciplines placed top priority on integrated libraries for accessing the literature and hel ping scientists to locate and understand information and data. For example, oceanographers commented that data were frequently separated from information about the data, but it was critical that "information about the algorithms used for a derived product, quality control procedures, comparisons with independent measurements, reviews by outside experts, and so on, be an inseparable part of the data so that the user could judge the reliability of the product for a particular application" (N ational Research Council, 1990, p. 238). 
$M$ assive amounts of data are generated daily, with even greater amounts anticipated in the near future; the concern is that the inaccessibility of data has reached crisis stage (see also Clery, 1993; M arshall, 1993; N RC , 1991a, 1994b). A well-functioning information system preserves data, and long-term stewardship of research data is essential. Associated with the archival function of a collaboratory are the functions of data distribution, data integration and new product development, data documentation provision, data quality assurance, data identification and acquisition, selective data retrieval to meet user needs, and standards development for procedures ( $\mathrm{N}$ ational Research Council, 1990, p. 235).

A comprehensive system of finding aids was recommended in order to support uniform manipulation (i.e. with one set of commands) of the heterogenous body of data and information generated by the information system. These include a variety of: "resource discovery" tools that help scientists locate and retrieve relevant data sources and applications programs [9]; and tools that systematically and efficiently relate and create the conceptual linkages across and between multiple, diverse, distributed and complexly-structured databases, and allow the individual user to "implement logical linkages between related items in different sources" (N ational Research Council, 1994b, p. 58; for extended discussions of these concepts, see Bright et al., 1992; $N$ ational Research C ouncil, 1990; Pechura and M artin, 1991; Pool, 1993; Schatz, 1987, 1992; W iederhold, 1992).

\section{Software sharing}

The C ommittee on a $\mathrm{N}$ ational Collaboratory emphasized a collaboratory capability for software related to data analysis: sharing of software, application of external (i.e. not local) software to data, and application of local software to external data ( $\mathrm{N}$ ational Research $\mathrm{C}$ ouncil, 1993, pp. 58-9). The software capability must include visualization for graphical display of complex multi-dimensional data. A prior step requires, of course, that data be organized and managed in distributed databases, and accessible through similar protocols, as noted above. Scientists also expressed the desire to have at a wide-area-network level the same multi-functional software that exists in the personal computer environment, which provides the capability to integrate databases, word processing, electronic mail and spreadsheets, as well as other types of software for computer-supported cooperative work, for access to shared data and computing resources ( $\mathrm{N}$ ational Research $\mathrm{C}$ ouncil, 1993, p. 40).

\section{Controlling remote instruments}

Physical scientists, such as oceanographers and space and earth physicists, require a collaboratory capability for remotely controlling instruments and collecting data. For example, oceanographers employ remotely operated vehicles, satellite-borne sensors, trace chemical measurement, acoustic techniques, long-life buoys and floats, and sea-floor seismometers to gather time series measurements ( $\mathrm{N}$ ational Research Council, 1994b, p. 8; see also $\mathrm{N}$ ational Research C ouncil, 1993). Space and earth physicists collect delayed and real-time viewing data from multiple sensors in aircraft, spacecraft, satellites, and ground-based facilities worldwide in a distributed system that operates internationally (see G reen and K ing, 1986; M arshall, 1993; $N$ ational Research Council, 1993).

\section{Communicating with remote colleagues}

The fourth essential capability for collaboration identified by the NRC is communication with colleagues. T he report commented that, "T he support of interpersonal interaction among a group of collaborators may be the most challenging aspect of collaboratory construction" because it " potentially includes access to remote data, programs, and instruments, as well as to multimedia work-group communications systems" and "also requires an understanding of the complexity and vicissitudes of human behavior" (N ational Research Council, 1993, pp. 60-1). T he basic tasks of scientific communication are multi-faceted and include:

- project organization and management;

- conduct of experiments;

- discussion and evaluation of findings;

- analysis of data;

- scientific review and commentary of discoveries;

- authoring, editing, publication, and review of documents; and 
- organization of and participation in scientific conferences.

C onsequently, applications to support these activities are diverse, such as electronic mail, bulletin boards, conferencing systems, file and document storage and retrieval systems, and computer-supported groupware ( $\mathrm{N}$ ational Research C ouncil, 1993, p. 61).

\section{Human resources to design a collaboratory}

T he collaboratory concept derives from a set of assumptions by science elites regarding the nature of scientific communication and how scientific advances take place. T hree aspects of a communication relation link scientists.

The first is that scientists collaborate because they are members of a subspecialty or subdiscipline that shares a similar intellectual framework, values and a common language, and agrees on the central problems facing the members and what constitutes the array of legitimate methodologies for problem solving (a "paradigm")[10]. Collaboration may occur intermittently, be short term, or take place over a long period of time. The dynamic that defines cohesion and the temporal conditions for the relationship is problem driven. Scientists, for example, may organize around:

- an organism as in the case of molecular biologists (Schatz, 1992);

- the development of a new technology, as in the case of the computer scientists who designed the Bitnet electronic network (C otter, 1988);

- the development of a new application, such as the programming language C OM M ON LISP (Steele, 1984); or

- the design of a new product in a cooperative university-industrial venture.

T hus, Schatz suggests that two fundamental requirements must be met by members of a subspeciality in order to form an electronic scientific community: they must " have a large amount of data, both formal and informal, and a real need to manipulate these data extensively" (Schatz, 1992, p. 92).

A second aspect of the communication relation is that the boundaries of disciplines and subspecialties are typically not permeable, and groups tend to operate in isolation from one another. $L$ anguage and cognitive understandings play very important roles in maintaining the boundaries of, and impeding communication between, disciplines or subspecialties. For example, Pechura and M artin (1991) observed that, when neuroscientists and computer scientists were brought together, "Beyond the expected difficulties of language (i.e., certain words mean one thing to neuroscientists and something entirely different to computer scientists), there were often fundamental differences in the perceptual frameworks used by the two groups". O ne outcome of the impermeable nature of the boundaries is that similar scientific discoveries may be independently derived or that inefficient solutions to a problem are developed because sufficient expertise is lacking ( $N$ ational Research C ouncil, 1993).

A third aspect of the communication relation as it relates to scientific advances and interdisciplinary or intersubspeciality interaction is that members of the subspecialty must recognize that the information they need to solve their particular problem might be obtained by communicating outside their area of specialization. The motivation to seek out other scientists may be internally derived by a desire for originality (see C rane, 1969), an understanding about relationships between fields, or externally driven by agents who provide an intellectual or monetary incentive[11]. T he assumption is that the action of communicating outside the area of specialization influences the development of new specialties that span boundaries and which are linked by critical individuals whom we call boundary-spanners (Allen, 1970) who provide the linkages. In this way, research will become more interdisciplinary, and a research area will advance by integrating different special izations (see U S C ongress, 1988, p. 35). D ifferent organizational models of research then develop, and that research takes place in units other than academic departments and includes more highly specialized work groups and shared infrastructure.

The $\mathrm{N}$ ational R esearch $\mathrm{C}$ ouncil reports underscore science elites' particular vision of advances in the scientific enterprise: that the intellectual boundaries of the disciplines must become more permeable in order to advance science and expand our knowledge base. C oupled with these assumptions about the communication relation is also a premise about 
scientific productivity: interdisciplinary research enables scientists to address more complex problems more successfully, and thereby enhances their productivity. The collaboratory concept reflects the scientific establishment's most explicit statement to date that broad benefits derived from the application of information technology, i.e. new knowledge and productivity, require a different conception of how science is conducted. Specifically, the collaboratory requires a "more explicit partnership between scientists in general and computer scientists in particular" (N ational Research C ouncil, 1993, p. 1), a different reward structure for discipline scientists who engage in its infrastructure design and implementation activities, and new interdisciplinary training (see also U S Congress, 1988).

\section{The organization of human resources to maintain and develop the collaboratory}

While advances in technology certainly allow scientists to probe more complex problems more deeply, these advances also create a demand for greater human resources (U S C ongress, 1988). Tasks associated with design, maintenance, evolution, coordination, and assistance in the use of computer-based facilities alter the size and composition of the traditional research project approach[12]. O perating a collaboratory more closely resembles an industrial model of research: production units with substantially varied and special ized competencies, including library management, information science, scientific database design and administration, computer science, engineering, as well as the particular research specialty, research program administration, and program evaluation.

\section{Human resources to support education of scientists and users}

Scientists do not come with a toolkit of technical competencies or expertise into which they reach to build and use collaboratories that will make possible effective and efficient data collection and analysis, communication and collaboration, and information storage and retrieval. $T$ he panel reports identify education as an important element of collaboratory design and functioning ( $\mathrm{N}$ ational A cademy of Sciences et al., 1989; N ational Research C ouncil, 1993). Two types of educational programs are needed.
The first is designed to educate and train the people who will build the collaboratory. The second program of education is designed to educate and train the scientists who will use the collaboratory for their research projects.

\section{Part two: SIPPACCESS, an information system for complex data for the 1984 Survey of Income and Program Participation}

Two events coincided during the 1980s that made the development of SIPP AC CESS possible. The first was the initiation of a new national longitudinal panel survey conducted by the US Bureau of the C ensus, the Survey of I ncomeand Program Participation (SIPP), and the second was a recognition that longitudinal panel surveys had become intractable and very difficult to manage. This section of the article:

- Discusses the mission, goals and objectives of SIPP ACCESS infrastructure development.

- Identifies the outcomes of an information system for complex data (ISC D) that were anticipated by the project.

- D escribes the information infrastructure that was created to organize statistical data for dynamic analysis and to share the accumulated formal and informal knowledge about complex data by an electronic community of economists, sociologists and demographers.

$\mathrm{N}$ ext we selectively describe the human resources applied to designing and maintaining SIPP ACCESS and the activities related to supporting the education of SIPP ACCESS users and other social scientists. T his section concludes with an evaluation of selected aspects of one implementation objective: achieving gains in scientific productivity through a central shared data facility.

\section{Introduction}

Following intensive research, planning and development during the 1970s and a delay due to severe governmental budget reductions in the early 1980s, the U S Bureau of the Census began fielding a major new government statistical series in the fall of 1983, the Survey of I ncome and Program Participation. The SIP P was designed as a series of longitudinal panel surveys to study income distribution, economic 
well being, and eligibility for and participation in government social welfare programs (see C itro and K alton, 1993; Ryscavage, 1987). $G$ reat enthusiasm for the survey - accompanied by a certain amount of hyperbole - was manifested by the statistical and social science research and policy communities.

$\mathrm{N}$ evertheless, immediately from the survey's inception, throughout the decade of the 1980s and into the early 1990s, SIPP was subjected to a barrage of critical public evaluation by social science researchers, policy analysts and the federal statistical community itself (see e.g. Aaron, 1985; Citro \& K alton, 1993; D avid, 1983, 1985; D oyle and D al rymple, 1988; Farley and $\mathrm{N}$ eidert, 1989; F lory et al., 1989; Jabine, 1990; $K$ ing et al., 1988; $M$ arquis and $M$ oore, 1990; N ational Research Council, 1989). T he criticism was on a broad scale; topics examined included whether its original objectives had been met, its usefulness as a vehicle for quickly responding to new public policy issues, quality of the SIPP data, the Bureau's design and management of its data processing system and data distribution procedures, the complex structure and usability of the Bureau's public data use products, timeliness of public data distribution, and responsiveness of the federal agency to the survey's many stakeholders and user communities.

Concurrently, increasing national concern was articulated, particularly by social science elites and federal funding agency program managers, that a substantial national investment had been made in longitudinal panel surveys whose use had been significantly less than anticipated. T he Bureau's serious problems with designing and managing a modern data processing system for the SIPP, the extensive delays in obtaining the data files experienced by analysts both inside and outside the Bureau, and the great difficulties that analysts had in understanding and processing the data prior to performing statistical analysis were also problems experienced by everyone who had used large longitudinal panel surveys (e.g. the Panel Study of I ncome $D$ ynamics ( PSID ), the $\mathrm{N}$ ational $L$ ongitudinal Survey of $L$ abor $M$ arket Experience ( N L S), the $\mathrm{N}$ ational Survey of the H igh School Class of 1972, and the R etirement $\mathrm{H}$ istory Survey).
It was also clear to some social scientists that the complexity of these data and the conditions under which most social scientists operated would continue to preclude use of longitudinal panel data. First, the intellectual and capital investment required for exploiting these data had been lacking. Second, the size, scope and complexity of these data were significant impediments to timely and efficient access and retrieval. T hird, appropriate technologies for efficient and low-cost data reorganization and retrieval, communication of scientific information, and exchange of data were largely unavailable to the social research community. And, fourth, the existing social science infrastructure for conducting research and policy analysis was not designed to respond optimally to the dynamic environment of data production, distribution and utilization.

\section{Goals and objectives of SI PP ACCESS infrastructure development}

In late 1984, we proposed a prototype of an information infrastructure to stimulate the production and sharing of knowledge about a complex dataset by social scientists in a research network to the $\mathrm{N}$ ational Science Foundation[13]. Weaknesses in the models for distributing statistical data led us to conceptualize an integrated information system that would enhance scientific productivity and efficiency. SIPP ACCESS, an information system for complex data, was designed as a model for timely and efficient access to and retrieval of complex data, and as a solution for communicating about data by mobilizing computer and telecommunications technology and creating a scientific infrastructure in an electronic network environment. The model was consciously designed to be generalized and applied by members of the social research community to complex datasets other than the two datasets that were ultimately incorporated into the information system. Four implementation goals were identified:

(1) efficient access to data;

(2) enhanced scientific communication and feedback among data producer, project staff and analysts;

(3) diffusion of information about and adoption of new technologies for analyzing complex data; and 
(4) application of newly available software, computer and communication technologies to large-scale, complex data.

Anticipated outcomes included:

- improvements in data quality;

- a new generation of social researchers trained to employ new technologies for managing large-scale, complex data;

- increased scientific productivity because the cost of access would be reduced, the scientific design of the data would be clarified, and research results would be more rapidly produced; and

- new knowledge about social-science infrastructure development through our own research and experimentation.

An electronic research network to stimulate scientific communication, cooperation, and data sharing for an electronic community of social researchers and policy analysts in government, universities and the private sector was created in A pril 1985, and over the next several years more than 200 people participated. The critical relationship between the data producer and user community via SIPP ACCESS was represented by the Bureau of the Census's membership in the research network.

\section{Design of an information system for complex data}

The ISCD 's infrastructure was designed to integrate information, statistical data, computers, software, and communication networks. $D$ iscoveries made by analysts, project staff and data producers about the statistical data became part of the knowledge resource of the ISCD. F igure 1 shows: the knowledge production system and relationships between and among the knowledge resources (data and information about data); the data producer responsible for producing and updating the data and preparing the documentation; the project staff who served as the expert intermediary between the users, the data producer, and the knowledge resource, and who were responsible for maintaining quality control, developing user interfaces, and enhancing the data; and the user/analyst who might be a sociologist, economist or demographer. The information system incorporated: capabilities of data and information management, search and retrieval; library and archival
Figure 1 Know ledge resources and knowledge-producing components of the ISCD

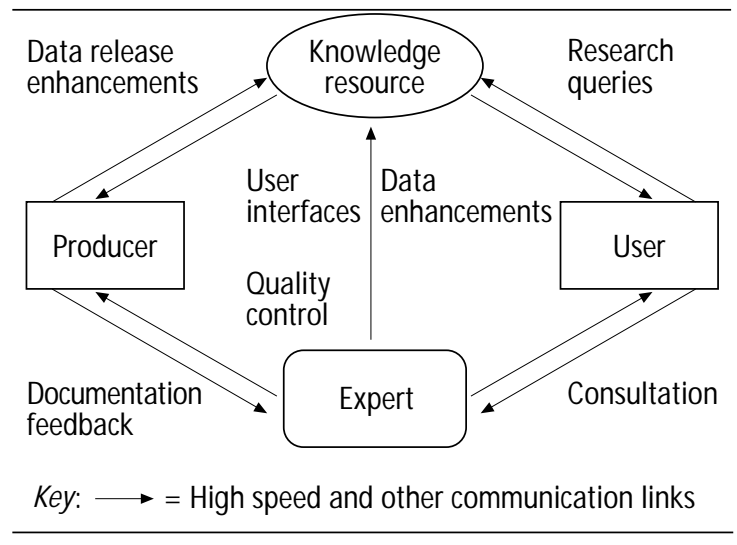

storage for data and information; and communications of news related to results and problem identification and solving.

Two longitudinal panel surveys, the Income Survey D evelopment Program (ISD P) and the 1984 Survey of Income and Program Participation (SIPP), produced by the U S Bureau of the C ensus were selected as test datasets[14]. The SIPP continues to be viewed as perhaps the most complicated set of survey data ever created. The first release of the complete panel of the 1984 SIPP contained about seven million observations and more than 20,000 variables (attributes) that represent 36 months of data for sample members. $L$ ater reorganization of the dataset, which also included additional variables by the Bureau of the $C$ ensus, increased the size of the dataset by about a third. M ultiple versions of the data files were released, reflecting errors that were identified and corrected. (Although subsequent annually-fielded panels were smaller in size, the aggregated quantity of data reached well over $12 \mathrm{~GB}$ of data in less than four years.) In size, of course, the 1984 SI P P dataset is far, far smaller than the terabytes of data routinely collected by space science projects, but it is structurally more complex because, in part, of the heterogeneity of and variations in measurements, analysis units, aggregations, and the multiple concepts of time embedded in the data.

Technical infrastructure

SIPP ACC ESS operated in a "distributed" computing environment which linked a variety of technologies. These included electronic networks, mini- and microcomputers, optical 
storage devices, and commercially-developed minicomputer and microcomputer relational database management systems. T he system included the primary node of the central data facility located at the $U$ niversity of $W$ isconsin$M$ adison Physical Sciences $L$ aboratory (PSL) and secondary nodes where members of the research network of analysts were located. The primary node maintained the archival data on laser disk, a relational database management system (RD BM S) with the complete and sample databases, statistical packages, applications programs designed to make complex operations transparent to the end-users, libraries of reference documents and data documentation, menu-driven help files that reported new developments in the database and user discoveries about the data, and electronic mail for communicating with the project staff. T he primary and secondary nodes were linked via the I nternet for electronic communication and file transfer. The secondary nodes cloned the database management capabilities of the principal node with a microcomputer version of the relational database management system. The RD BM S contained four relational databases:

(1) ISDPRUN (complete panel data),

(2) ISD PTEST (2 percent sample of complete panel data),

(3) SIPPRUN (complete panel data), and

(4) SIPPTEST (2 percent sample of complete panel data).

T hese data are further explained below.

Information storage and retrieval: integration of metadata and statistical data

The information system integrated statistical data and metadata (information about the data). T he metadata included information on the database design, logical structure, and contents (e.g. characteristics of the variables);

- survey design;

- field operations and processing procedures;

- reference materials; and

- the results of data analysis.

It provided the linkage between attributes in the database to the variables in the original public use files and hel ped users locate relevant variables for cross-sectional or longitudinal analysis. $D$ ata dictionary utilities, accessible from inside the database, provided details on the meaning of attributes and tables.

\section{D ata management}

A pplications programming was devoted to developing a relational database and user utilities to facilitate access to and retrieval of information and data. That is, the project relied on off-the-shelf tools, and the project did not allocate resources to design and develop technology. Instead, staff resources were spent designing the intellectual structures required to access complex data.

A database schema was developed to exploit the semantic principles implicit in the data collection process (for an extended discussion, see $D$ avid and Robbin, 1990, 1992). The crosssectional SIPP data were reorganized and transformed into time-series, longitudinal summaries, events, and new units of analysis in response to analysis needs. Relational principles also led to large-scale reductions in data storage. $\mathrm{N}$ ew data structures were designed to facilitate an understanding of the complexity of longitudinal panel surveys, reduce conceptual errors, and obtain large reductions in the amount of time required to prepare data for longitudinal panel analysis. Summary data were developed to facilitate dynamic analysis of panel data.

We designed and prototyped a sample (test) database called SIPPT EST, a 2 percent representative sample of sample units in wave one (first interview), including all subunits (e.g. households, families, and persons) and attributes associated with these units from waves one through nine extracted from the complete panel dataset. Although only a 2 percent sample of a very large database, SIPPTEST contained more cases than most national sample surveys. SIPPT EST was also used to prototype the design of a relational database for the complete panel database SIP PRUN, whose logical structure was identical to that of SIPPT EST. T he only difference between SIPPTEST and SIPPRUN, was that SIPPTEST contained the metadata and a sample of statistical data, whereas SIPPRU N contained only the complete panel statistical tables. The SIPPT EST concept was later extended to a microcomputer version that was distributed internationally, in order to reduce reliance on remote access to the central data facility and to 
remove institutional constraints on using a

"foreign" or remote computer.

$D$ ata storage and retrieval

SIPPT EST resided online 24 hours a day. In contrast, the large complete panel database

SIPPRU N was maintained offline, located on an optical archive store (OAS) laser disk. Analysts independently retrieved data from the OAS into the database.

\section{Communication}

T heSIPP ACCESS information system provided a variety of informational tools about the data. These included:

- interactive, menu-driven help utilities;

- bulletin boards signaling new additions to the databases and errors discovered in the data by project staff and users; and

- libraries of work in progress, reports, publications, and reference materials prepared by the data producers, analysts and SIPP ACCESS project staff.

T he electronic network provided the principal vehicle for analysts, project staff, data producer, and technical staffs from multiple sites to communicate with one another. T he online project staff consultant (SIPPASSIST) assisted in problem solving, and the online liaison with the Bureau of the Census served as an invaluable source for understanding SIPP and tracking down answers inside the Bureau of the $C$ ensus. (See Robbin (1992) for a description of the communication flows that took place.)

\section{Human resources to design, maintain and develop SIPP ACCESS}

The principal staff of project directors, postdoctoral level, doctoral and pre-doctoral students; and the database administrator were what computer scientists call "domain specialists". $T$ he core staff consisted of social scientists with specialties in income and wealth distribution, demography, geography, information science and organizational behavior. O ur primary scientific training and experiences as social scientists pertained to the substance of the data managed in the ISCD. T he social scientists were supplemented by programming, clerical and library management staff.

The project staff were responsible for designing and implementing the information system and identifying user needs for the ISDP and SIPP data in a relational database management system environment. The conceptual issues about data related principally to their longitudinal nature and representation in a RD BM S (e.g. how to enhance the data to assure the linkage and integrity of longitudinally relevant samples over time). D atabase implementation issues related to the large number of observations and variables in the surveys that needed to be processed (e.g. how to process quantities of data on an ad hoc basis and at the same time maintain the integrity of the database). TheSIPPTEST database was used by the project staff to learn about the ISDP and SIPP and the RDBM S environment, test queries, develop new table structures, debug command files, and so on. For example, developmental work was carried out to identify missing data and to design efficient procedures for identifying and linking individuals across waves and for identifying the set of persons relevant for any type of longitudinal analysis. Selected data were reformatted as event tables and as time series to enhance the longitudinality of the data. We developed a procedure for converting measurement (survey) time to real (calendar) time because they are not identical in the ISDP and SIPP (owing to the structure of the questionnaire and the staggered interviewing of four subsamples).

Our conceptual framework underlying SIPP ACCESS identified the analyst as the central focus of information system and database design. T hese needs included identifying appropriate hardware and software for the user community, creating retrieval tools and a networking capability, handling production requests for the complete sample after users had completed their experimentation on the test database, and accessing the PSL and retrieving SIPP data from remote sites. We prepared tools which facilitated system access, information and data retrieval and communication between the project staff and users and among users, and which also reduced the amount of detail users were required to know in order to understand the operating system and RD BM S. SIPPT EST was designed as an inexpensive tool to learn about the SIPP and RD BM S. M enu-driven help was the available. O nline consulting was provided through electronic mail. 
Experimentation with technologies also took place and later led to a variety of tools to make data transfer and retrieval simple and transparent to users. An automated recordkeeping system was developed to monitor use of the SIPP ACCESS facility, databases and computational resource expenditures. Electronic communications (electronic mail) between users and the project staff were archived for future analysis (see Robbin, 1992). Audit trails were designed to serve as a permanent record of the decisions made during the design phase. In 1988 , our evaluation of the design, implementation, use and cost of the SIPP relational database and SIPP ACCESS led to a redesigned logical structure for theSIPP database and the development of a RD BM S microcomputer version of the SIPPTEST database. This objective extended our experimentation to additional technology and to newly-available applications software. PC-SIPPTEST was released to the public after beta testing and extensive preparation and revision of documentation. The design requirements for a 1985 SIPP panel database were also analyzed; our primary interest was testing whether metadata developed for the 1984 panel could "drive" the loading of a new panel database - a fundamental modification of the procedures for developing a database. We also devised a strategy for permanent archiving of the history of the project in a form which would be available for public review. T he SIPP ACCESS project was formally completed in D ecember 1991, although use of the SIPP databases continues.

\section{Human resources to support education of SIPP ACCESS users and other social scientists}

T he sample database SIPPT EST was designed with multiple learning objectives in mind, such as:

- clarifying fuzzy research questions;

- understanding the scientific design of the SIPP;

- exploring the metadata and data; and

- testing understandings and hypotheses about the policy problem under investigation before analysts prepared extracts from the SIPPRU N complete panel database.
The sample database provided rapid interaction with the data at low cost and reduced the future costs of using the complete panel database SIPPRUN.

D iffusing information about the SIPP and SIPP ACCESS and encouraging adoption of the new relational database technology were implemented through a teaching program and reference and consulting services for the SIPP and the SIPP ACCESS project. We recognized that, if researchers and policy analysts were to take advantage of SIPP ACC ESS, we needed to teach the intricate design of the SIPP, the skills of remote computing and communication, and the special theory of relational data management. Three- and four-day workshops to communicate knowledge about theSIPP and the new technologies of the SIPP ACCESS information system were held in $M$ adison and at other sites throughout the U SA between 1985 and 1991. We also served as a national resource for researchers who planned to use the SIPP data or wanted information about the RDBM S and database design, and also made a concerted effort to publicize the SIPP ACCESS data facility through participation in national and international conferences and workshops.

\section{Achieving gains in efficiency, scientific productivity and collaboration through an ISCD}

The first implementation objective of SIP P ACCESS was to achieve gains in scientific productivity by improving access to large-scale, complex data. While measures of gains in scientific productivity are elusive (see U S C ongress, 1986) [15], our evaluation focusses on performance, that is, scientific activity, and outputs that resulted from the SIPP ACCESS data facility. These outputs are multi-dimensional and reflect direct and indirect products of the scientific research process, which is stimulated by data facilities like SIPP ACCESS[16]. This section discusses three tangible outputs that are evidence of SIPP AC C ESS performance: data products, client use of the facility, and intellectual networks. T his section evaluates the complete panel SIPPRU N relational database in terms of the performance dimension of "feasibility", describes results from some of the intensive monitoring of the information system that we carried out, and examines the 
intellectual network of scholars created by SIPP ACCESS.

$D$ ata products of SIPP ACCESS: completepanel relational database SIPPRU N

T he data products of the Survey of Incomeand P rogram Participation were evaluated according to four performance dimensions: feasibility, portability, user demand and cost; however, this discussion addresses only the dimension of feasibility for the complete panel relational database SIPPRU N. D ata quality and enhancements that occurred through SIPP ACCESS are then briefly examined.

F easibility was strongly questioned at the outset of the project; some analysts argued that RD BM S were inappropriate for large datasets (D oyle, 1989; D oyle et al., 1987). T he production of SIPPRUN as a relational database demonstrated that it was feasible to use RD BM S technology for longitudinal panel data (see also Wells, 1991). T he relational model yielded two important efficiencies: large-scale reduction in data storage and the ability to retrieve small subsets of data on an as-needed basis. $\mathrm{N}$ ormalization reduced the more than $2.2 \mathrm{~GB}$ of the original public use data files by 75 percent. T he logical structure of the database partitioned the vast quantity of statistical data into a few categories which organized the variables (attributes) by their semantic meaning in individual tables; thus, only a small subset of the entire dataset had to be searched and retrieved in a database query. T his reorganization also reflects the way in which analysts work: analysis is typically carried out on a subset of the population and a very small subset of the very large number of variables. Reorganizing the database to include time aggregations resulted in a net reduction in the volume of data requested by each analyst. T hese enhancements greatly reduced the computation required to estimate dynamic models using the data, as well as the chance for analysts' errors arising from the ambiguous statements about relevant universes that appear in official Bureau of the $C$ ensus documentation.

Table I illustrates the relationship between retrievals of data and efficiencies gained in reorganizing the original public use files into a relational database. Columns (1)-(4) describe two different kinds of information on income that are collected by the SIPP: income and amounts from social programs (including food stamps, social security, veterans, and welfare for head of the program unit and its members), and assets income type (labeled B through F) and amounts for individuals and couples. Columns (5) and (6) describe the number of retrievals made on these data and the relationship between retrievals and number of tables which contained the data.

The original public data files were distributed by the Bureau of the $C$ ensus in two formats: one called "REC tangular" and the second called "REL ational" (a misnomer because the file structure was basically hierarchical). TheSIPP ACCESS project obtained the files in a REL ational format, which contained all program income on one record (labeled the $\mathrm{G} 1$ record by the $C$ ensus Bureau) and all assets income on another record (labeled the $\mathrm{G} 2$ record). D uring Phase $O$ ne of database development, we loaded all the program receipt and income data for heads and membership into nine tables (one table per interview) and all the asset income for individuals and couples into nine tables (each table represented one interview, of which there were nine during the life of the survey) - just as these records were distributed by the $C$ ensus Bureau. Column (1) shows the size of the files as distributed by the $C$ ensus $B$ ureau in phase one in the REC tangular format $(N \cong 400,000$ ) and in the REL ational format $(\mathrm{N} \cong 161,000)$. Column (1) then shows the result of restructuring the data in phase two. The significant difference between phase one and phase two databases is that the restructured phase two database contained information only for sample relevant units of analysis (e.g. of the total sample of more than 161,000 persons, there were only 12,090 food stamp units and 2,577 mothers receiving WIC assistance). Column (2) records the number of tables that were created for each unit. Column (3) indicates the number of variables associated with the unit of analysis (e.g. 26 variables for 12,090 heads of a food stamp unit; 15 variables for 2,577 WIC recipients). Reading across to column (4) shows that the phase one program data in the REC tangular format occupied about $98.40 \mathrm{M} \mathrm{b}$ and the REL ational public use file occupied about 39.61M b. ( $T$ he significant difference between the two phase one structures is explained by the fact that the 
Table I Density of access for selected phase one and phase two tables

\begin{tabular}{|c|c|c|c|c|c|c|}
\hline Table type ${ }^{a}$ & $\begin{array}{c}\text { Sample } \\
\text { size }^{b} \\
1 \\
\end{array}$ & $\begin{array}{c}\text { Number of } \\
\text { tables } \\
2\end{array}$ & $\begin{array}{c}\text { Number of } \\
\text { variables } \\
3\end{array}$ & $\begin{array}{c}\text { Number of } \\
\mathrm{Mb}^{\mathrm{C}} \\
4\end{array}$ & $\begin{array}{c}\text { Number of } \\
\text { retrievals } \\
5\end{array}$ & $\begin{array}{c}\text { Density } \\
\text { (col 5/col 2) } \\
6\end{array}$ \\
\hline \multicolumn{7}{|c|}{ Program receipt income (G1 record) } \\
\hline \multirow[t]{2}{*}{ Phase one } & $\begin{array}{l}\text { otal sample: } \\
400,000 \text { (REC) }\end{array}$ & & & 98.40 & & \\
\hline & 161,000 (REL) & :L) & 999 & 39.61 & 46 & 5.1 \\
\hline Phase two: & e relevant & 11 & 232 & 10.72 & 61 & 5.5 \\
\hline Food stamps (head unit) & 12,090 & 1 & 26 & 0.58 & 5 & 5.0 \\
\hline Food stamps (members) & 2,808 & 1 & 14 & 0.08 & 4 & 4.0 \\
\hline Social security (unit head) & 57,356 & 1 & 57 & 5.60 & 6 & 6.0 \\
\hline Social security (members) & 887 & 1 & 9 & 0.02 & 2 & 2.0 \\
\hline Veterans (head unit) & 5,824 & 1 & 26 & 0.34 & 7 & 7.0 \\
\hline Veterans (membership) & 3,825 & 1 & 13 & 0.11 & 4 & 4.0 \\
\hline Welfare (head unit) & 7,696 & 1 & 25 & 0.44 & 6 & 6.0 \\
\hline Welfare (members) & 3,896 & 1 & 13 & 0.11 & 3 & 3.0 \\
\hline Other welfare (head unit) & 60,546 & 1 & 19 & 3.35 & 10 & 10.0 \\
\hline $\begin{array}{l}\text { Women, infants and children } \\
\text { (WIC) (head unit) }\end{array}$ & 2,577 & 1 & 15 & 0.06 & 4 & 4.0 \\
\hline Social security (couples) & 877 & 1 & 15 & 0.03 & 10 & 10.0 \\
\hline
\end{tabular}

Asset receipt/income (G2 record)

\begin{tabular}{|c|c|c|c|c|c|c|}
\hline \multirow[t]{2}{*}{ Phase one } & $\begin{array}{c}\text { Total sample: } \\
N=400,000 \text { (REC) }\end{array}$ & Total sample: & & 192.40 & & \multirow[b]{2}{*}{2.5} \\
\hline & $N=222,000$ (REL) & 18 & 1,926 & 106.78 & 47 & \\
\hline Phase two: & Sample relevant: & 10 & 119 & 16.15 & 40 & 4.0 \\
\hline Part B (individuals) & 192,421 & 1 & 16 & 9.27 & 7 & 7.0 \\
\hline Part C (individuals) & 19,326 & 1 & 16 & 0.90 & 7 & 7.0 \\
\hline Part D (individuals) & 36,182 & 1 & 17 & 2.15 & 7 & 7.0 \\
\hline Part E (individuals) & 13,279 & 1 & 20 & 0.90 & 7 & 7.0 \\
\hline Part F (individuals) & 13,279 & 1 & 17 & 0.86 & 7 & 7.0 \\
\hline Part B (couples) & 55,277 & 1 & 5 & 0.91 & 1 & 1.0 \\
\hline Part C (couples) & 4,947 & 1 & 5 & 0.90 & 1 & 1.0 \\
\hline Part D (couples) & 7,139 & 1 & 7 & 0.08 & 1 & 1.0 \\
\hline Part E (couples) & 6,664 & 1 & 7 & 0.15 & 1 & 1.0 \\
\hline Part F (couples) & 2,051 & 1 & 5 & 0.03 & 1 & 1.0 \\
\hline \multicolumn{7}{|c|}{ Notes: } \\
\hline \multirow{2}{*}{\multicolumn{7}{|c|}{$\begin{array}{l}\text { a The database was developed in two stages (phases), with the phase one logical structure most closely resem- } \\
\text { bling the original public use data files. Phase two represents the results of semantic analysis and normalization } \\
\text { The Bureau of the Census adopted a naming convention for these two record types: the "G1 record" represent- } \\
\text { ed program income receipt and amounts and the " } G 2 \text { record", assets income receipt and amounts } \\
\text { b Two sample sizes are calculated (rectangular format, relational format). We use } N=400,000 \text { as an estimate of } \\
\text { total number of sample persons less attrition and noninterviews that appear in the rectangular (REC) format } \\
\text { public use files. We use } N=20,000 \text { as an estimate of sample persons less attrition and noninterviews for the } \\
\text { relational (REL) format. Calculations take account of reduced sample sizes in relevant waves. The much smaller } \\
\text { sample size of the relational (REL) format reflects the fact that the public use data file was organized by record } \\
\text { types (G1, G2) }\end{array}$}} \\
\hline & & & & & & \\
\hline \multicolumn{7}{|c|}{$\begin{array}{l}\text { c Megabytes for phase one data were calculated by multiplying the number of observations by the number of } \\
\text { characters in the } \mathrm{G}(N=246) \text { or } G 2(N=481) \text { record }\end{array}$} \\
\hline
\end{tabular}


program income and assets income items in the questionnaire are relevant to only a very small part of the entire sample because most people do not receive program support and most people have little assets income. $M$ ost of the space in the REC tangular files was filled with "not-in-universe" (NIU) values.) Column 4 also shows the result of the phase two normalization for program income: size decreases from 39.61-10.72M b. Column (5) shows the number of recorded retrievals by researchers in phases one and two. For example, researchers made a total of 46 retrievals to the $G 1$ record in phase one, and, after restructuring in phase two, made a total of 61 retrievals. But the real significance is that researchers were actually retrieving data for a particular program type (e.g. food stamps, Aid to $F$ amilies of $D$ ependant $C$ hildren (AFDC), etc.). T he ratio of retrievals to table increases (the term "density"), as shown in column (6).

The lower half of Table I also shows similar differences for the asset receipt and income data. In phase one the original public use data occupied 18 database tables. Both the rectangular and relational public use files had large amounts of N IU s because the sequentially organized public use files had to reserve space for a particular asset income question, whether or not that question was relevant to a person. We reorganized the asset income data according to asset type and significantly reduced the size of the tables: from 192.40M b for the REC tangular and $106.78 \mathrm{M} \mathrm{b}$ for the RE $L$ ational formats to $16.15 \mathrm{M} \mathrm{b}$ for the restructured data tables.

In other words, restructuring had many benefits because only a very small amount of data had to be retrieved to study a very small subset of the welfare or assets-holding population. The effect of reorganizing (normalizing) the original data was a significant reduction in the size of a table and a significant decrease in physical storage size of the database. Table I supports the contention that different parts of the data were retrieved differentially, from which we infer that only subsets of the data were of interest to the analysts (the analyses described in the publications produced by SIPP ACCESS users confirm this fact as well).

$U$ sers of the SIPP databases were largely unaware of the role that SIPP ACCESS played in establishing the quality of the SIPP data. At numerous points in the history of the 1984 SIPP Panel, SIPPRU N generated different statistics than control totals, and it was later determined that the Bureau of the $C$ ensus public use files were in error. SIPPRU N also uncovered inconsistencies among counts; that is, totals generated from different parts of the scientific design were not logically possible. Feedback to the Bureau of the $C$ ensus resulted in revisions to the public use datasets in most cases. Subsequent updating of SIPPRU N (and SIPPT EST) provided immediate correction to research underway. Researchers were informed of changes in the database in bulletins posted at the time that researchers logged on the system. The results of monitoring quality were cumulative and embedded directly in the SIPPRUN database. Information about all known corrections and known inconsistencies was online, available to everyone who logged into SIPP ACCESS. SIPP ACCESS provided a clearinghouse for purging bad data from research use. This level of monitoring and public cumulation of information did not occur in future SIPP databases or public use files released by the Bureau of the $C$ ensus.

G etting results: how was SI PP ACCESS used? TheSIPP ACCESS information system was extensively monitored, including system logons, accesses to the databases, and retrievals of data from optical storage. The cost of using SIPP ACCESS was monitored through the central node's accounting system. Computer mail directed to SIPP ACCESS was archived. In this part of the article use of theSIPP ACCESS system is described, with primary emphasis on logons to the information system, accesses to the SIPPTEST and SIPPRUN databases, and retrievals of data from the optical archive. Table II provides an overview of how the information system was used.

Over the life of SIPP ACCESS there were 203 individuals who were authorized to use SIPP ACCESS at the central node (the PSL) (row (A) of Table II). T hese were project holders whom we assigned a unique user name. Sixty analysts (user names) were associated with the 41 accounts established at the PSL to use SIPP ACCESS after workshop training (row $\left.A^{\prime}\right)$. Typical users would first learn how to use SIPP ACCESS through SIPP ACCESS-funded workshop accounts. They would then establish 
Table II M easures of SIPPACCESS activity and their interrelationships

\begin{tabular}{lccccc}
\hline & $\begin{array}{c}\text { Measure } \\
\text { of use }\end{array}$ & $\begin{array}{c}\text { Project user } \\
\text { counts }\end{array}$ & $\begin{array}{c}\text { Density } \\
\text { of use }\end{array}$ & $\begin{array}{c}\text { Intensity per access } \\
\text { (1) / (2) }\end{array}$ \\
Definition \\
Dimension & $(1)$ & (2) & (3) & Ratio & (4) \\
\hline
\end{tabular}

\section{Clients}

(A) PSL project holders ${ }^{\mathrm{a}}$

$\left(A^{\prime}\right)$ With own account ${ }^{b}$

PSL system access ${ }^{C}$

(B) System logons

Database access

(C) All (PSL, IRP)

(D) SIPPIEST

(E) SIPPRUN

Optical storage access (PSL, IRP)

6,379
14,455

2,743

45

$151(248)$
$105(193)$
$46(55)$

121

138

61

314

$0.31 \mathrm{D} 1 / \mathrm{Cl}$

$0.69 \mathrm{D} 1 / \mathrm{Cl}$

\section{(F) OAS accesses}

\section{Communication}

\section{(G) E-mail (client, data}

\section{producer, SIPP ACCESS staff)}

Notes:

a Includes everyone who ever established a computer account at the central node (PSL) - 131 were workshop participants

b Includes analysts who established a PSL computer account independently of having attended a training workshop

C System logons include only those clients who used SIPPACCESS through PSL. Use of PSL by Institute for Research on Poverty (IRP) analysts would be reflected in these system logon counts if an IRP analyst attended a training workshop or bought time on the PSL computer when the IRP computer became clogged. Analysts could have project accounts associated with both PSL and IRP between 1986 and 1990, depending on the time period they were associated with IRP

d All SIPPRUN users are SIPPTEST users. The SIPPTEST counts exclude 88 persons (workshop attendees and others who used the SIPPTEST database before April 1987 and SIPPACCESS staff for the entire project). We have recorded SIPPRUN accesses for 46 individuals, but a total of 55 analysts, including SIPP ACCESS staff, used the SIPPRUN database; density is calculated on a base of 46 . Counts indicated in parentheses reflect total number of SIPPRUN users

their own project accounts. A particular research investigation on a project account could span several funding sources or be a small component of a single project account. Accesses to the SIPP ACCESS system are a clearer measure of use. Row (B) in Table II shows that the 163 users generated an average number of 121 accesses to the system. ( $\mathrm{N}$ ote that, although 203 people were authorized users, logons were recorded for only 80 percent of them.)
We obtained a more precise measure of SIPP ACCESS use by monitoring access to the two databases SIPPT EST and SIPPRU N. D atabase accesses is a minimal measure of the role of SIPP ACCESS, since much statistical analysis based on the system derived from, but did not make use of, the databases because it was carried out at the analyst's site. The number of accesses to the databases exceeds the number of logons. T his result may seem paradoxical. T he 
explanation lies in the fact that a database could be accessed several times during one system access; that is, for example, during one session at the PSL, queries were first developed and tested in SIPPT EST database, after which a production job was submitted using the SIPP RU N database.

Table Il shows that only half of the unique users ever logged on to the databases after we began recording database accesses. T he primary reason is that 131 of the 203 SIPP ACCESS authorized users were associated with workshop activity, but a total of only 60 people were associated with user-funded project accounts. Some workshop participants never accessed the databases (they worked in groups and delegated data entry to someone in the group). In addition, some principal investigators were authorized SIPP ACCESS users but assigned all database work to research assistants. The average number of database retrievals per database user is 138 . We will refer to the ratio of retrievals to use as a measure of density (e.g. 151 project users made a total of 20,834 retrievals from the databases for a density of use equal to 138). This density is higher than the average number of system logons per user (a density equal to 121), because the number of database users is smaller than the number of system users. $M$ ore than two-thirds of database usage represented calls to SIPPRUN. Row (F) of Tablell shows access to the OAS archival storage where theSIPPRU N tables were stored as files. As might be expected, the density of OAS use is lower than SIPPRU N use: multiple tables were retrieved once from the archival store, but, once loaded in the database, researchers made multiple retrievals from these tables. This fact is quantified in the intensity column - column (4) - as the ratio 0.19.

$M$ onitoring retrievals from the OAS was hel pful in deciding which portions of the original public use data files warranted reorganizing to improve the efficiency of user queries. O ur monitoring also confirmed that analysts were principally carrying out longitudinal analysis of the SIPP data and that only a small subset of the total database was frequently retrieved by users. $M$ any tables in the SIPP database were seldom addressed; thus the relational organization segregated data that were not needed and provided easy access to data of research interest[17].
Electronic mail generated 1,646 messages to or from the SIPP ACC ESS staff. That count includes messages with substantive content pertaining to the SIPP, the databases, use of SIPP ACCESS information services, and research strategy. Those messages were analyzed by Robbin (1992). Their existence is reported in Tablell to underscore the fact that monitoring activity required monitoring communication as well as the use of databases.

Client output and scientific activity The design of SIPP ACCESS as a research network implied the fostering or reinforcing of an intellectual network of scholars. Table III examines the research output in terms of publication authorship and the institutions that participated in research through 1990 using the SIPP ACCESS ISCD. The total number of publications in this table includes SIPP ACCESS project staff papers if they resulted from secondary analysis of the data; we have removed 22 staff papers that deal largely with the design of SIPP ACCESS, resulting in a base of 147 papers. We coded private, for-profit and not-for-profit institutions as "private"; disaggregating the private institutions would give us a total of 22 different institutions that used SIPP ACCESS, rather than the 19 that we show in the table.

We derive several insights from this table. $M$ ore than 50 percent of the research output was produced by individual authors; 29 percent were jointly authored at the same institution; and 14 percent jointly authored at different institutions. F our institutions, $U$ niversity of $W$ isconsin-M adison, B rown U niversity, Bowdoin College, and Brandeis U niversity, account for nearly three-quarters of the total research output during the first six years of SIPP ACCESS. As might be expected, because of the location of the Institute for R esearch on Poverty and a long history of poverty research, the $U$ niversity of Wisconsin-M adison produces slightly more than one third of the total number of papers. Researchers at nine of the 22 institutions had intellectual ties to the Institute, either as graduate students or affiliates who participated in poverty research through grants or contracts.

We conclude that the SIPP ACCESS facility reinforced an existing national network of 
Table III Research output and intellectual netw orks

\begin{tabular}{|c|c|c|c|c|}
\hline Institution ${ }^{a}$ & $\begin{array}{c}\text { Sole } \\
\text { authorb }\end{array}$ & $\begin{array}{c}\text { Joint } \\
\text { authorc }\end{array}$ & $\begin{array}{l}\text { Joint author } \\
\text { outside author's } \\
\text { own institutionc }\end{array}$ & $\begin{array}{c}\text { Number of } \\
\text { publications }\end{array}$ \\
\hline \multicolumn{5}{|l|}{ University of Wisconsin- } \\
\hline Madison & 38 & 10 & 5 & 55 \\
\hline Brown & 3 & 16 & 5 & 24 \\
\hline Bowdoin & 15 & 1 & & 16 \\
\hline Brandeis & 7 & & 5 & 12 \\
\hline Sub total & 63 & 27 & 15 & 107 \\
\hline Percentage grand total & & & & 73 \\
\hline Private $^{d}$ & 3 & 4 & & 7 \\
\hline Maryland & 5 & & 1 & 6 \\
\hline Columbia & 1 & 2 & 1 & 4 \\
\hline Indiana & 2 & 2 & & 4 \\
\hline \multicolumn{5}{|l|}{ University of } \\
\hline North Carolina & 2 & 2 & & 4 \\
\hline Duke & 1 & 2 & & 3 \\
\hline Government/agency & 2 & 1 & & 3 \\
\hline Cornell & & 2 & & 2 \\
\hline Central Florida & 2 & & & 2 \\
\hline \multicolumn{5}{|l|}{ University of } \\
\hline California, Davis & 2 & & & 2 \\
\hline Northwestern & 1 & & & 1 \\
\hline Oregon State & 1 & & & 1 \\
\hline South Adelaide & & & 1 & 1 \\
\hline Vassar & 1 & & & 1 \\
\hline $\begin{array}{l}\text { University of California at } \\
\text { Los Angeles }\end{array}$ & & 1 & & 1 \\
\hline Totals & 86 & 43 & 18 & $147^{e}$ \\
\hline Percent & 57 & 29 & 14 & 100 \\
\hline
\end{tabular}

Notes:

a Institution is where author was first located if publication is produced within one year after first publication; if publication is dated two or more years after date at first location, the author is coded as located at the second institution. This situation occurred most frequently with graduate students who completed their work and took positions elsewhere. Authors on temporary leave from their home institutions are coded as members of their home institutions even if they produced a publication while on leave

b Production of a publication took place at the sole or joint authors' home institution

c Publication is coded as "joint authorship with author at another institution" if second or third author was formerly a member of another institution

d Includes four institutions

e The total numbers of papers produced by users of SIPPACCESS is 169. We include papers produced by SIPP ACCESS project staff in this table if the paper resulted from secondary analysis of the SIPP data but exclude 22 staff papers that dealt largely with the design of the information system 
poverty researchers. At the same time, however, Table III also shows that the SIPP ACCESS network succeeded in enlarging this small network of poverty researchers by providing a resource to a larger group of institutions, none of which had previous ties to the $U$ niversity of W isconsin-M adison. (See also $\mathrm{H}$ esse et al. (1993) for evidence of the importance of the electronic network for researchers at the "periphery" of scientific activity.)

\section{Part three: SIPPACCESS: a model of a collaboratory for the social sciences? Obstacles to collaboratory development}

D id SIPP AC CESS, an ISCD, meet the operational definitions and criteria for a collaboratory for scientific research? T he answer is affirmative for the conceptual framework and model that led to the design of the information system, but the complete range of knowledge and functionality in an all-inclusive network system discussed in the first section of this article and advocated by Schatz (1992) was not achieved. $T$ he latter was, in part, a function of timing, of a historical moment - the limited availability of appropriate telecommunications, computational and applications software, and its occurence in the 1990s, an era of declining funding for social scientific infrastructure research, development and experimentation. C ertainly, an adequate funding base was a critical obstacle to achieving a SIPP AC CESS collaboratory.

Still, even in its six years, SIPP ACCESS did not cause/achieve the sociological change advocated by the science elites. Computer scientists were not directly involved in the project (one served on the $\mathrm{N}$ ational Board, however), and an electronic community model along the lines advocated by Schatz was not explicitly adopted as an organizing principle and institutionalized for the conduct of research by others in the social science community[18]. Part three examines some of the conceptual/technical, cognitive, social-psychological, and sociological obstacles to developing an institutionalized collaboratory for the social sciences:

- integrating heterogeneous databases;

- cognitive, experiential knowledge, and other attributes of users;

- collaboration between computer scientists and domain specialists; and
- cumulative advantage of institutions.

What social scientists have learned from research into innovation diffusion and adoption is relevant here.

\section{Conceptual/technical obstacles to integrating heterogeneous databases}

Social scientists face problems similar to those faced by space physicists, brain scientists or oceanographers, in that they want to relate and integrate in a common information system multiple databases whose information representation and structures are different. Wiederhold explains that:

For single databases, a primary hindrance for enduser access is the volume of data that is becoming available, the lack of abstraction, and the need to understand the representation of the data. [But] when information is combined from multiple databases, the major concern is the mismatch encountered in information representation and structures (1992, p. 38).

F or example, the $\mathrm{N}$ ational L ibrary of $\mathrm{M}$ edicine would like to provide social scientists with Internet access to its large and complex series of annual and biannual health surveys which have digitized $X$-rays associated with the medical examinations that doctors carried out and the statistical data that derive from the questionnaires administered to nationally representative samples of households. There are, of course, technical problems of data storage, transfer and management accompanying digitized $X$-ray data and gigabytes of historical data. But it is the creation of an integrated information system of $X$-rays, statistical data, and the textual materials associated with multiple designs, implementation, processing, and analysis of the surveys and other data - the sum total of raw, calibrated, validated, derived and interpreted data - that is fundamentally, conceptually difficult.

The problems associated with the task are very subtle and concern the idiosyncratic cognitive reasoning process that establishes a relationship between data and knowledge resources, which may well go beyond what can reasonably be obtained from integrated libraries. F or example, what organizing structure for the information should be used? H ow do we represent the complexity and multi-dimensional aspects of the data? H ow do we specify the theoretical connections among specific areas of interest, 
which will certainly be idiosyncratic given the diversity of interests of social and behavioral scientists and the potential of these data to support many different research applications? It is clear that new concepts, techniques and functionalities must be developed to support the interoperability and integration of autonomous, semantically heterogeneous database systems with unique conceptual schema in order for a diverse community of scientists to operate effectively in a distributed network environment. Solutions are not immediately obvious to the complex array of severe problems of fusion and semantic inconsistency, although work is being carried out on "mediators" that embody administrative, technical and scientific domain knowledge (see W iederhold, 1992).

\section{Different cognitive, experiential knowledge, and other attributes of users}

Effective use of the SIPP ACCESS information

system required extensive knowledge in a large number of general and specific content domains. One set of content domains included the policy problem under investigation, survey design, statistics, programming, software and computation (knowledge acquired in formal training through course work, although social scientists rarely study programming formally and typically learn to use statistical software and the computer as part of their academic training in their disciplines). Proficiency in using data required a second set of content domains that included knowledge of data structure, data management, and the grammar of a query language for operating on the data (knowledge formally taught in computer science and management information systems courses; social scientists typically rely on programmers for this kind of expertise). A third set of knowledge was specific to the datasets, the software and computational environments in which the data were located, and the complex interrelationships of data, software and computational environment (knowledge gained through direct experience, although only a few social scientists have a detailed understanding of the computational environment and the relationships between data and software, and software and the computer).

The SIPP AC CESS project staff instituted an instructional program which assumed that users had prior knowledge and experience in the subject matter of the first set of knowledge domains. The program was designed to assist users in acquiring facts and procedural skills in the second and third sets of subject domains. We recognized that a workshop setting was inadequate for integrating the vast amount of background information required for using the SIPP ACCESS system and, instead, concentrated on communicating essential information (organized in a handbook) that would provide users with a basis for acquiring the skills necessary to learn on their own after the workshop, supplemented with assistance in problem solving provided by the online consultant SIPPASSIST. T he instructional strategy was a "scaffold" to foster autonomous learning skills: to teach students (faculty, researchers, programmers, project assistants and policy analysts) what they needed to know and how to acquire and process information, that is, effective strategies and procedures for locating information and for problem solving.

Contrary to our initial expectations about the skill level of workshop attendees, however, we discovered that social scientists came to the ISC D with widely varying and considerably different analytical, methodological, statistical and technical competencies, and these deficiencies could never be overcome. But there are also other attributes that influenced whether or not researchers adopted the SIPP ACCESS innovation.

A cognitive capacity to process new and particularly complex information was an important factor. Complexity inhibited use by novices who had attended our workshops and was an even more severe impediment for users who had not participated in these workshops. O nly the most highly sophisticated data analysts could be expected to use the SIPP ACCESS facility. $R$ esearchers who were successful had a repertoire of compiled knowledge that was extensive: substantial knowledge about large datasets, survey design, statistics, and policy issues, and also extensive experience in using computers and statistical and other software. For them, the information system created greater efficiencies and improved effectiveness over standard statistical and data management systems (see B aker, 1989).

M otivation to use the SIPP AC CESS facility outside of the controlled environment of the 
workshop also influenced acceptance and use of the innovation. U sing SIPP AC CESS required that the individual be flexible and playful about adopting an innovation. A nalysts who went on to use the SIPP ACCESS facility after a workshop approached the idea of a relational database and the learning that was required as a "new and interesting game". U sing SIPP ACCESS and the relational database were "fun", and SIPP ACCESS was an opportunity to add to their storehouses of knowledge. We did not appreciate the extent to which people were resistant to altering their past behavior and how difficult it was to adopt an innovation when new mental models and new ways of working were required.

U sing SIPP ACCESS also required a very large investment of time, and the learning curve could be steep and long. A nalysts who were prepared to make the investment in learning went on to use the complete panel database after a workshop. As one graduate student, an independent learner, said, "You know that you have a lot of work to do when you start something you've never done before". O nly a few participants were willing to invest time and energy to do so. It was not that the SIPP ACCESS system was too complicated to learn. Rather, it was a rational calculation that the new technology carried certain high costs in learning and information overload relative to the potential benefits of increased productivity, improvements in understanding the data, greater precision in data retrieval, and higher quality statistical analysis. Analysts "minimized loss" in the short-run by making the decision not to use the new technology. We did not anticipate this benefit-cost calculation, however informal, associated with learning.

$\mathrm{H}$ aving a well-formulated research problem was also a strong incentive to use SIPP ACCESS. Workshop participants who had a well-defined research problem for which the SIPP was applicable went on to use SI PPRU N . A well-defined research problem meant that prior planning had already taken place, even if complete knowledge of the SIPP data was not yet in place. $M$ any workshop participants came to a workshop because they had heard or read about the SIPP ; they did not come with a specific policy problem worked out in advance for which the SIPP could be used, and only a very few succeeded in working out a problem in the months following a workshop.

The ability to work autonomously without a face-to-face social network appears to be important factor in using an electronic network. Although the electronic network provides significant capabilities for enhancing the analytical capabilities of the end-user, the distributed client/server system and services approach places considerable responsibility on the enduser to navigate successfully. T his environment requires not only a high level of computer sophistication, but it also requires people who rely minimally on others for solutions to problems. $N$ early all the successful SIPP AC CESS users from outside of the $U$ niversity of $W$ isconsin-M adison were like this. Their e-mail messages indicated that they relied primarily on their own resources to solve problems and called for help only after they had tried a variety of alternate procedures to solve their problems. We did not appreciate the importance of selfreliance until we observed that our $W$ isconsin graduate students, only two of whom had attended a workshop, learned about SIPP and the relational technology from one another. Every day, graduate students spent many hours together in the computer room. They taught the SIPP to each other; more experienced SIPP users helped novices solve problems; and they shared their programs and scripts with one another. They created their own support network. We concluded that autonomous individuals will perform effectively in an electronic network environment. For others, peer reinforcement to learn about and use the SIPP after the workshop will be an important factor that influences use of a collaboratory-type network facility. F or the less autonomous individual, the electronic network environment may not successfully provide this important social-psychological component to learning. As such, an electronic network and frequent communication with project staff may not be able to substitute for the traditional modes of scientific work where geographical proximity is perceived as necessary.

\section{Collaboration between computer scientists and social scientists}

The reports of the $\mathrm{N}$ ational A cademy of Sciences, $\mathrm{N}$ ational Research $\mathrm{C}$ ouncil, $\mathrm{N}$ ational 
Science F oundation, and O ffice of Technology Assessment emphasize how critical it is to bring together domain specialists, computer scientists and informatics specialists in order to "realize the information future" and respond effectively to its challenges. TheSIPP ACCESS project directors recognized prior to the inception of the project, that development of the information system would require the collaboration of computer scientists. D uring the six-year period we attempted to interest both faculty members and graduate students in computer science in the project but were ultimately never successful. $M$ ost often, the problems we identified were summarily dismissed as "uninteresting". T here was a certain irony in hearing this, particularly because at about the same time, but in isolation, computer scientists were also acknowledging a variety of problems that social scientists had already attended to or had written publicly about for more than a decade: locating and accessing heterogeneous scientific data, archiving and preservation, development of metadata, adequate description and documentation, development of standards for data, data citation and proprietary datasets, and structures to represent appropriately time and spatial data, (see e.g. F rench et al., 1990; Scheuermann et al., 1989; Silberschatz et al., 1990). The irony is reinforced when reviewing the $\mathrm{N}$ ational Collaboratories ( $\mathrm{N}$ ational Research C ouncil, 1993); which completely ignored any collaboratory-enhancing work carried out by social scientists[19].

The resistance of computer scientists is a critical obstacle to implementing the recommendations of the science panels for the creation of collaboratories. It has, as we discovered from our SIPP ACCESS experience, its origins in the different languages used to define what constitutes important problems of the different disciplines. Similarly, we also learned that few social scientists could identify their data management and other related computational problems as being amenable to solutions which computer scientists were eminently suited to develop. D uring the six years we al so heard regularly from social science colleagues that we were "wasting precious time that should be devoted to "doing research'"; building infrastructure was not rewarded by the social-science community. F rom our experience it can also be said that we discovered few computer scientists or social scientists who were interested in attempting effective communication across the boundaries of the two disciplines. There were indeed, as Pechura and M artin (1991) observed when neuroscientists and computer scientists were brought together, "fundamental differences in the perceptual frameworks" because each discipline approaches its work differently. It is doubtful that external agents such as funding agencies, which are ostensibly committed to programs across disciplinary boundaries, will be able to alter the situation. The impermeability of specialty boundaries is great, differences in the reward structures are great, and boundary spanners will have to be highly trained in the domains of social science and computer science in order to recognize how solutions derived from different disciplines can be brought to bear on the problem at hand.

\section{Cumulative advantage}

We have al ready noted that SIPP ACCESS users were differentially advantaged with regard to knowledge and social-psychological attributes. Successful SI PP ACC ESS users were those who had accumulated significant advantage related to the knowledge domains required for manipulating complex data in a relational database and networked environment, and they were similarly advantaged in their approaches to adopting an innovation. There is, however, another aspect to cumulative advantage that is a significant obstacle to any widespread collaboratory development in the social sciences and also in the other sciences.

Institutions also accumulate advantage and disadvantage. This cumulative advantage means that a variety of resources are institutionally supplied to the researcher so that high scientific productivity is made possible (see Allison and Long, 1990, for statistical evidence of the effect of institutional infrastructure). M erton writes that these resources include: "access to needed equipment, an abundance of able assistance, time institutionally set aside for research, and, above all else perhaps, a cognitive microenvironment composed of colleagues at the research front who are themselves evokers of excellence, bringing out the best in the people around them (1988, p. 615)." H igh-impact papers are produced by institutions which have extensively 
invested in infrastructure (see Science, 1994b), and it is these institutions which continue to attract, as M erton noted, "far larger resources of every kind, human and material" (1988, p. 617). (See also annual reports of the $N$ ational Science F oundation that discuss the allocation of academic science and engineering research and development funds for evidence that only ten institutions account for about 25 percent of federal research funding.)

D uring the six years of the SIPP ACCESS project, we discovered that an institutional infrastructure that has the capacity to support the conduct of research was a critical factor in whether analysts could or did use the SIPP data or the SIPP ACCESS facility. Institutional policies and rules governing who had access to these resources also influenced subsequent use of SIPP ACCESS. M ost workshop participants who logged on to PSL after the workshop and used the complete panel database SIPPRU N worked at an institution whose infrastructure made research on complex data possible. These were institutions with a research mission or with a physical plant that facilitated the research activity. Computational facilities were extensive, communications systems were modern, computing was either free or low cost, and personnel dedicated to supporting the research mission were available. In addition, these researchers had access to either external or internal funds for purchasing data, carrying out research, buying time on another computer, and making long distance telephone calls to access PSL ( prior to Telnet access). Without this institutional infrastructure and access to either internal or extramural support in real dollars, workshop participants could not be expected to use SIPP ACCESS in the future.

This infrastructure could be in place, but whether the workshop participant had access to it was a critical determinant of future use of SIPP ACCESS. Institutional policies and rules also played an important role. For example, informal and formal policies typically provided university funds only to faculty, which excluded use by graduate students. Policies also prohibited use of external facilities when these facilities "duplicated services" at one's own institution; improved productivity and efficiency offered by SIPP ACCESS were deemed irrelevant. At the beginning of the project, we did not appreciate the very large effect that an individual's institutional environment would have on future use of SIPP ACCESS. Probably more than any other factor for many analysts, deficiencies in the social setting in which everyday research and teaching activities take place explain why interest in SIPP ACCESS did not translate into use.

$T$ he message seems clear: institutional information infrastructure development and the provision of appropriate facilities for educating a student body are so extraordinarily investmentintensive that only a few elite institutions can be expected to have the resources to do so. $\mathrm{C}$ an countervailing processes reduce the institutional monopoly or domination by a few institutions, to use M erton's language (1988, p. 619)? $M$ erton argued that institutional advantage also meant "being located at strategic nodes in the networks of scientific communication that provide ready access to information at the frontiers of research". We have al ready shown that electronic networks can compensate somewhat for the lack of these institutional resources. Although there appears to be some evidence that individual departments can achieve improvements in their intellectual capacity in a relatively brief time, it does not appear that ready access to information, which in itself requires infrastructure investment, can compensate for the lack of institutional resources which $M$ erton identified as critical for the conduct of scientific activity on the frontiers of research. As the $\mathrm{N}$ ational Research $\mathrm{C}$ ouncil $\mathrm{C}$ omputer Science and Telecommunications B oard noted in its report, "significant numbers of highereducation institutions remain with limited or no Internet access" (N ational Research C ouncil, 1994a, p. 121).

Finally, cumulative institutional advantage interacts with the culture of the various specialties of the social sciences and the rewards for social scientific activity by science elites. E vidence of the social-science community's capacity to develop electronic communities-cumcollaboratories might be assessed by examining the extent to which collaborative, interinstitutional research is carried out. The $\mathrm{N}$ ational Science Foundation D ivision of Social, Behavioral, and E conomic Research grant list for fiscal year 1994 was reviewed. While comparative data on physical scientists and the nature of their research activities are needed to assess with 
mount this type of effort, other changes have been observed in the intervening years that create optimism for the future, although these changes have largely been in the technical area.

For example, database designers have now developed nearly transparent and standard interfaces between statistical packages and RD BM Ss, and the major statistical package SAS now incorporates the capability to create relational databases. Graphical user interfaces greatly enhance the user's capability to access and use data. Relational database management system designers have begun to understand the deficits of the relational model which impede use of scientific databases.

D esigners of data repositories and data libraries have begun to recognize that client/ server approaches require a new end-user philosophy: the database must support whatever type of interface, system or analysis the end-user desires. $M$ anagers of data repositories have automated the evaluation of data quality, the development of documentation, and the distribution of their datastores. End-users are being provided with powerful tools for automated access, processing, modification and display of data on their desktop computers. Advanced systems even provide cooperative computation services, so that the host will help the end-user's computer, working collaboratively to process data for display on the end-user's machine, in the end-user's chosen format or application.

To respond to deficits in the infrastructure of higher education, some federal agencies and private foundations are providing support for infrastructure development and enhancements, as well as providing support for integrating computer technology into the curriculum and for educating computer-literate students. T here appears to be a growing recognition that literacy and national economic renewal and global competitiveness are intimately related to each other. I ncreasing constraints on available dollars to support the information infrastructure are leading to a recognition that, just as with library collections, public data collections can be multisite, geographically distributed and shared through an "interlibrary loan" capability that the Internet provides naturally.

Informatics specialists can take a leadership role in thinking about how to make the collaboratory a reality, thinking hard about organizing and managing the preservation of, access to, and widespread diffusion of data and information resources. Policy recommendations made by science elites regarding $\mathrm{K}-12$ and highereducational needs related to improving science education, as well as research into the behavioral and cognitive attributes of the user community and into how information is valued and used, need to be taken seriously and implemented. We need to focus more on communication flows and social networks and the posited datato-information-into-knowledge processes, particularly if we are to benefit from the potential of applications that enable the mass diffusion of processed information. A sea-change in thinking about, and the application of costefficiency to, academic infrastructure must take place by senior administrators in primary and secondary schools and in higher education. As William Wulf acknowledged, the "bottleneck to the achievement of vision [of a collaboratory] is not hardware" (Wulf, 1993).

\section{Notes}

1 The National Academy of Sciences et al. (1989, p. 1) defines information technology as the set of computer and telecommunications technologies that makes computation, communication, and storage and retrieval of information possible.

2 The Arpanet was established in 1969 as a computer netw ork-supported collaboration (National Research Council, 1993, p. 9). It is view ed, for example, that the programming language COM M ON LISP could never have been possible without the computer network (National Academy Sciences et al., 1989, p. 20). For some of the many published discussions about collaborative work using information technology that preceded Wulf's elaboration on the collaboratory concept, see Baker and Zwicki (1984), Bush (1945), Comer (1983), Green and King (1986), Greenstadt (1981), Lederberg (1978), President's Science Advisory Committee (1963), Rees et al. (1986), and Steele (1984).

3 See my abbreviated critique of the failure to address information infrastructure issues in Robbin (1992). The central importance of the content of information, information resource management, as well as the community of users, is also underscored by M cClure et al. (1991).

4 Lederberg commented that we had to acknow ledge that the human dimension of computers and communications was a " task of equal priority to engineering the hardware" (1978, p. 1318).

5 For the historical record it is also important to record that as early as the 1950s, at the height of the Cold War, 
geophysicists in the international community were persuaded that the future of their research agenda and the creation of new know ledge lay in formalizing a collaborative international infrastructure that linked people and instruments. (I am grateful to M arie Dvorzak, director, Geology-Geophysics Library, University of Wisconsin-Madison for this historical note on the international geophysical year.)

6 I use the word "new" in terms of the particular importance placed on cognitive capabilities and social structure as they relate to the content of what is produced by scientific activity, for which considerable research has been conducted on the scientific community by behavioral, social and information scientists, but not by physical scientists. Clearly, the concerns registered by the hard sciences about professionalization of their disciplines, careers and job training reflect attention to "human capital" issues. See, for example, the annual issue of Science magazine that is devoted to discussions of the future of the young scientist (e.g., Science 1994a). Similarly, efforts to measure the outputs of science, as part of the study of scientific productivity, reflect another dimension of interest in the study of " human capital" for which considerable research has been conducted. See, for example, US Congress (1986), Small (1990), Hesse et al. (1993).

7 Major advances that particularly affected the infrastructure development included information and data storage, management, retrieval and other applications software, local- and wide-area netw orks, distributed computing, and a variety of client/server approaches. The project staff and users would have benefitted from, for example: multiple platforms for relational database management systems (RDBMS) residing in a distributed computing environment; multiple-gigabyte CD-ROM and magnetic tape cartridge storage; powerful personal computers or workstations on which complete sample tables or the entire database itself could reside; seamless interfaces between the RDBMS and statistical packages; multimedia, including hypermedia; graphical user interfaces to facilitate user access to all components of the information system; and cooperative computational services.

8 The term "interoperability" was broadly applied by the 1993 National Research Council report and used in the context whereby, for example, experiments, data, models, graphical and tabular interpretation, textual summaries, documentation, and publications would be integrated and portable. "Transparency" was emphasized because of the physically distributed nature of the information, data, software, technologies, and human resources. The attribute of "customizability" was used to reflect the fact that users would want to be able to create "familiar" interfaces and impose restrictions on access to their own work. "Integrity" was recognized as a critical attribute because system and data security had to be maintained, but also because the quality of the information being submitted to the system had to be verified. "Extensibility" was required so that the system would continue to evolve and be able to incorporate dynamic changes in the technological environment as well as new services and features that would meet the scientists' research needs.

9 Examples of resource discovery browsing and display tools include Archie, Gopher, World Wide Web (and tools such as Mosaic, Netscape and Lynx), wide area information servers, and tools that are currently being prototyped, such as Essence (Hardy and Schwartz, 1993).

10 Chubin comments that the "key to conceptualizing the structure of specialties may be the nature of the communication relation used to link scientists" (1976, p. 451). Hagstrom suggests that members of a specialty can be identified by characteristics such as frequent and intense communication, exchange of preprints and reprints, and citation of one another's work (1970, p. 91).

11 A mathematician acquaintance once said to me, "The best scientists are those who see the relationships between fields - that they share concepts. That's how new fields develop, too". For example, the renaissance of geometry in the USA reinforces these insights (see the historical analysis of the differential geometer Osserman (1989)). The communication relation may also be motivated by some incentive provided by agents external to the specialty. External agents attempt to influence innovation adoption (i.e. interdisciplinary collaboration) by providing isolated groups with intellectual and monetary incentives for interacting with one another. Federal funding agencies, such as the National Science Foundation, and professional organizations, such as the American Association for the Advancement of Science, play a "nurturing" role and organize interdisciplinary conferences where scientists from different disciplines can talk to one another. The granting agencies use their budgets as instruments for mobilizing collaborative undertakings (see, e.g. the Directorate for Education and Human Resources at the National Science Foundation). External agents may also include private-sector firms which support $R \& D$ as a means to develop new products and services.

12 Considerable gaps in data collection about personnel make it difficult, how ever, to confirm that production units have actually been altered (USCongress, 1988), although anecdotal evidence suggests that technical tasks of programming and information management are handled by discipline-based scientists rather than computer scientists. The results of a study of funding support and the workforce for investigator-initiated research grants (R01) and program project grants (P01) by the US National Institutes of Health (NIH) (1993, pp. 1-2) for fiscal years 1983, 1985, 1987 and 1990 are instructive in this regard. The report states that the single most important factor in budget increases was personnel costs. Between 1983 and 1990, the average number of full-time equivalents (FTEs) per grant supported by the $\mathrm{NIH}$ increased from 2.99-3.33. But whereas, for example, estimated FTEs for more senior doctorates increased from 0.84 FTE to 1.08 per grant, there were decreases in the estimates for technical support ( 0.66 FTE per grant to 0.46 ) and other categories of staff (from 0.15-0.13 FTE) per grant. 
13 Martin David and Alice Robbin served as co-principal investigators and co-directors of the SIPP ACCESS project, and Thomas Flory as database administrator. Portions of the second part of this article have been excerpted from our Final Report to the NSF (David and Robbin, 1992). The SIPPACCESS project was supported in part by the National Science Foundation (SES8411785, SES-8921213 and SES-8701911), the Sloan Foundation (B1984-25 and B1987-46), the Social Science Research Council, the Bureau of the Census (through the National Science Foundation), and the University of Wisconsin-M adison. Administrative support was provided by the Institute for Research on Poverty and Center for Demography and Ecology (P30 HD05875) at the University of Wisconsin-M adison. We remain indebted to our first NSF program officer M urray Aborn for his wisdom, foresight and nurturing of this project.

14 Although our principal efforts (and most of the discussion in this article about these data) were devoted to the Survey of Income and Program Participation, a second set of data - the precursor to the SIPP - the Income Survey Development Program, was also incorporated into the information system and was used by researchers and policy analysts.

15 The Office of Technology Assessment (OTA) (US Congress, 1988) discusses the difficulties of relating $R \& D$ expenditures to scientific productivity or other economic benefits. It notes that the principal benefits of research, new and unexpected knowledge, cannot be assigned a direct economic benefit. Scientific activity has indirect effects, such as "spillovers" and "spinoffs", which are difficult to quantify. Our discussion does, however, utilize bibliometric measures, which are a principal noneconomic indicator of the "output of science", and follows the OTA's recommendation that it is necessary to attend to the process between inputs and outputs, that is, intermediate steps in the research activity. Andrews (1979) and his colleagues do, however, establish a broad set of indirect quantitative and qualitative " performance-effectiveness" indicators in their international study of scientific productivity.

16 A data facility may also produce indirect outputs in the form of scientific communication, improvements in data quality, the learning of new tools to be used for scientific investigation, and new knowledge about conceptual framew orks, methodologies, etc., that are applied elsewhere.

17 For example, during our evaluation of the phase one database structure (which resembled quite closely the structure of the original public use relational file), we noted that the heaviest retrievals were being made of 18 tables which contained interview status and demographic information on the sample. Our monitoring led to the creation of a table called retention, which summarized interview status and sample relevance, and a table called constants, which summarized fixed demographic information (e.g., birth date, gender, education), over the entire panel for all sample members. Thus the 36 tables that had to be retrieved were reduced to two tables in the redesigned (phase two) database.
18 This is not to say that inchoate electronic communities do not exist in social science. There are informal collectives of scientists who interact regularly because of their research on similar problems. The Internet stock market exchanges organized by economists over the past several years certainly meet the requirements for forming an electronic community: " a large amount of data, both formal and informal, and a real need to manipulate these data extensively" (Schatz, 1992, p. 92).

19 But there is also another explanation as to why social scientists' work was ignored, which has to do with the hierarchical nature of science and which fields do and do not have prestige and the resources associated with that prestige. The committees of the National Research Foundation, as well as science panels of the National Research Council and National Academy of Sciences, are dominated by the physical or " hard" sciences. In general, there is widespread disdain for "soft" or social and behavioral sciences.

20 Some indirect evidence of the extent of multi- or interinstitutional collaboration in the physical and life sciences is available in a recent report on the increase of multiauthor publications (Regalado, 1995).

\section{References and further reading}

Aaron, H. (1985), “Comments on 'Evaluation of Census Bureau procedures for the measurement of noncash benefits and the incidence of poverty', by Barry Chiswick", Proceedings of the Conference on the Measurement of Noncash Benefits, Vol. 1, US Bureau of the Census, Washington, DC, pp. 57-62.

Allen, T.J. (1970), "Roles in technical communication networks", in Neson, C.E. and Pollack, D.K. (Eds), Communication among scientists and engineers, Heath Lexington Books, Lexington, M A, pp. 191-208.

Allison, P.D. and Long, J.S. (1990), "Departmental effects on scientific productivity, American Sociological Review, Vol. 55, pp. 469-79.

Andrews, F.M . (Ed.) (1979), Scientific Productivity: The Effectiveness of Research Groups in Six Countries, Cambridge University Press, New York, NY.

Baker, S. (1989), “ University scientists crack high-tech welfare data shell", Computerworld, Vol. 22 No. 21, May 23, p. 18.

Baker, D.N. and Zwicki, R.D. (1984), "M eeting report: NASA data systems users", EOS, Vol. 65 No. 6, February 7 , p. 46.

Bright, M.W., Hurson, A.R. and Pakzad, S.H. (1992), "A taxonomy and current issues in multidatabase systems", Computer, Vol. 25 No. 3, pp. 50-9.

Bush, V. (1945), "As we may think", Atlantic M onthly, Vol. 176 No. 1, pp. 101-8.

Chubin, D.E. (1976), "The conceptualization of scientific specialties", The Sociological Quarterly, Vol. 17 No. 4, pp. 448-76. 
SIPPACCESS, an information system for complex data Alice Robbin

Cinkosky, M.J., Fickett, J.W., Gilna, P. and Burks, C. (1991), "Electronic data publishing and Genbank", Science, Vol. 252, May 31, pp. 1273-7.

Citro, C.F. and Kalton, G. (Eds) (1993), The Future of the Survey of Income and Program Participation, National Academy Press, Washington, DC.

Clery, D. (1993), "ERS-1: a cautionary tale of data overload", Science, Vol. 261, p. 847.

Comer, D. (1983), "The computer science research network CSNET: a history and status report", Communications of the ACM, Vol. 26 No. 8, August 13, pp. 747-53;

Committee on Physical, M athematical, and Engineering Sciences; Federal Coordinating Council for Science, Engineering, and Technology; and the Office of Science and Technology Policy (1992), Grand Challenges 1993: High Performance Computing and Communications, The FY 1993 US Research and Development Program (1992), supplement to the President's Fiscal Year 1993 Budget, Committee on Physical, M athematical, and Engineering Sciences; Federal Coordinating Council for Science, Engineering, and Technology; and the Office of Science and Technology Policy, Washington, DC.

Cotter, H. (1988), "Birth of a network: a history of BITNET", CUNY/University Computer Center Communications, Vol. 14, pp. 1-10.

Crane, D. (1969), "Social structure in a group of scientists: a test of the "invisible college" hypothesis" , American Sociological Review, Vol. 32 No. 5, pp. 335-52.

David, M.H. (Ed.) (1983), Technical, Conceptual, and Administrative Lessons of the Income Survey Development Program (ISDP): Papers Presented at a Conference, Social Science Research Council, New York, NY.

David, M.H. (1985), "The distribution of income in the United States: implications for the design of the SIPP panel", Journal of Economic and Social Measurement, Vol. 13 Nos. 3-4, Special Issue, pp. 305-17.

David, M.H., and Robbin, A. (1990), "Database design for large-scale, complex data", in Berk, K. and M alone, L. (Eds), Computing Science and Statistics. Proceedings of the 21st Symposium on the Interface Between Statistics and the Computer, American Statistical Association, Alexandria, VA, pp. 205-14.

David, M. and Robbin, A. (1992), Building New Infrastructures for the Social Science Enterprise. Final Report to the National Science Foundation on the SIPP ACCESS Project, November 1984 - December 1991, 2 Vols Institute for Research on Poverty, University of Wisconsin-Madison, Madison, WI, January.

Doyle, P. (1989), "Data base strategies for panel survey" , in Kasprzyk, D., Duncan, G., Kalton, G. and Singh, M.P. (Eds), Panel Surveys, John Wiley \& Sons, New York, NY, pp. $163-89$

Doyle, P. and Dalrymple, R. (1988), "The impact of imputation procedures on distributional characteristics of the low income population", Proceedings of the Third Annual Research Conference, US Bureau of the Census, Washington, DC, pp. 483-508.
Internet Research: Electronic Networking Applications and Policy

$$
\text { Volume } 5 \cdot \text { Number } 2 \cdot 1995 \cdot 37-66
$$

Doyle, P., Citro, C. and Cohen, R.L. (1987), Feasibility Study of Long-term Access to SIPP, M athematica Policy Research, Inc, Washington, DC, July.

Farley, R. and Neidert, L.J. (1989), "Analyzing the characteristics of blacks: a comparison of data from SIPP and CPS", 1988 Proceedings of the Social Statistics Section, American Statistical Association, Alexandria, VA, pp. 103-8

Flory, T.S., Martini, A. and Robbin, A. (1989), "Spells of AFDC receipt in the 1984 SIPP Panel", 1988 Proceedings of the Social Statistics Section, American Statistical Association, Alexandria, VA, pp. 267-72.

French, J.C., Jones, A.K. and Pfaltz, J.L. (Eds) (1990), Scientific Database Management (Final Report), Report of the Invitational NSF Workshop on Scientific Database Management, M arch 1990, Charlottesville, VA (Computer Science Report No. TR-90-21), Department of Computer Science, University of Virginia, Charlottesville, VA, August.

Green, J.L. and King, J.H. (1986), "Behind the scenes during a comet encounter" , EOS, Vol. 67 No. 9, March 4, pp. 105, 11.

Greenstadt, E.W. (1981), " Data systems users working group" , EOS, Vol. 62 No. 5, February 10, p. 50.

Hagstrom, W.O. (1970), "Factors related to the use of different modes of publishing research in four scientific fields", in Nelson, C.E. and, Pollock, D.K. (Eds), Communication among Scientists and Engineers, D.C. Heath, Lexington, MA, pp. 87-124.

Hardy, D.R. and Schwartz, M.F. (1993), "Essence: a resource discovery system based on semantic file indexing", 1993 Winter USENIX, San Diego, CA, January 25-29, 1993, pp. 361-73,

Hesse, B.W., Sproull, L.S., Kiesler, S.B. and Walsh, J.P. (1993), "Returns to science: computer networks in oceanography" , Communications of the ACM, Vol. 36 No. 8 , pp. 90-101.

Jabine, T.B. (1990), Quality Profile. Survey of Income and Program Participation, US Department of Commerce, Bureau of the Census, Washington, DC, May.

King, K.E., Petroni, R.J. and Singh, R.P. (1988), "Data quality of the Survey of Income and Program Participation", 1987 Proceedings of the Section on Survey Research Methods, American Statistical Association, Alexandria, VA, pp. 221-6.

Lander, E.S., Langridge, R. and Saccocio, D.M . (1991), "Mapping and interpreting biological information", Communications of the ACM, Vol. 34 No. 11, pp. 33-9.

Lederberg, J. (1978), "Digital communications and the conduct of science: the new literacy", Proceedings of the IEEE, Vol. 66 No. 11, pp. 1314-19.

McClure, C.R., Bertot, J.C. and Zweizig, D.L. (1994), Public Libraries and the Internet: Study Results, Policy Issues, and Recommendations, US National Commission on Libraries and Information Science, Washington, DC, June. 
SIPPACCESS, an information system for complex data Alice Robbin

McClure, C.R., Bishop, A.P., Doty, P. and Rosenbaum, H. (1991), The National Research and Education Network (NREN): Research and Policy Perspectives, Ablex Publishing Corporation, Norw ood, NJ.

Marquis, K.H. and M oore, J.C. (1990), "M easurement errors in SIPP program reports", Proceedings of the Sixth Annual Research Conference, US Department of Commerce, Bureau of the Census, Washington, DC, pp. 721-45

Marshall, E. (1993), " Fitting planet Earth into a user-friendly database", Science, Vol. 261, August 13, pp. 846, 848.

Merton, R.K. (1988), " The Matthew effect in science, II: cumulative advantage and the symbolism of intellectual property" , ISIS, Vol. 79 No. 299, pp. 606-23.

National Academy of Sciences; National Academy of Engineering; Institute of Medicine; Committee on Science, Engineering, and Public Policy (1989), Information Technology and the Conduct of Research: The User's View, Report of the Panel on Information Technology and the Conduct of Research, National Academy Press, Washington, DC.

National Research Council (Committee on National Statistics) (1989), The Survey of Income and Program Participation - An Interim Assessment, National Academy Press, Washington, DC.

National Research Council (Committee on Global Change US National Committee for the IGBP - of the Commission on Geosciences, Environment, and Resources) (1990), Research Strategies for the US Global Change Research Program, National Academy Press, Washington, DC.

National Research Council (Committee on Arctic Solid-Earth Geosciences; Polar Research Board; and Commission on Geosciences, Environment, and Resources) (1991a), Opportunities and Priorities in Arctic Geoscience, National Academy Press, Washington, DC.

National Research Council (Panel on a Global Netw ork of Fiducial Sites. Committee on Geodesy; Board on Earth Sciences and Resources; Commission on Geosciences, Environment, and Resources) (1991b), International Network of Global Fiducial Stations: Science and Implementation Issues, National Academy Press, Washington, DC.

National Research Council (Committee on a National Collaboratory: Establishing the User-Developer Partnership) (1993), National Collaboratories: Applying Information Technology for Scientific Research, National Academy Press, Washington, DC.

National Research Council (NRENAISSANCE Committee) (1994a), Realizing the Information Future: The Internet and Beyond, National Academy Press, Washington, DC.

National Research Council (Commission on Geosciences, Environment, and Resources; Ocean Studies Board) (1994b), The Ocean's Role in Global Change: Progress of Major Research Programs, National Academy Press, Washington, DC.

National Science Foundation (1994c), Division of Social, Behavioral, and Economic Research Grant List. Fiscal
Internet Research: Electronic Networking Applications and Policy

$$
\text { Volume } 5 \cdot \text { Number } 2 \cdot 1995 \cdot 37-66
$$

Year 1994 (October 1993 - September 1994 (draft)), National Science Foundation, Arlington, VA.

Osserman, R. (1989), "The geometry renaissance in America: 1938-1988" , in Askey, R., Duren, P.L. and Merzbach, U.C. (Eds), A Century of Mathematics in America. Part II, American Mathematical Society, Providence, RI, pp. 513-26.

Pechura, C.M . and Martin, J.B. (Eds) (1991), M apping the Brain and its Functions: Integrating Enabling Technologies into Neuroscience Research, National Academy Press, Washington, DC.

Pool, R. (1993), "Beyond databases and e-mail", Science, Vol. 261, August 13, pp. 841-3.

President's Science Advisory Committee (1963), Science, Government and Information, US Government Printing Office, Washington, DC, January 10.

Rees, D., Perla, I., Meredith, N.P., Green, J. and Van der Heijden, N. (1986), " Netw orking ground-based images of Comet Halley during the Giotto Encounter", EOS, Vol. 67 No. 50, December 16, pp. 1385-7.

Regalado, A. (1995), "M ultiauthor papers on the rise", Science, Vol. 268, April 7, p. 25.

Robbin, A. (1992), "Social scientists at work on electronic research netw orks", Electronic Netw orking: Research, Applications and Policy, Vol. 2 No. 2, pp. 6-30.

Ryscavage, P. (1987), SIPP: Filling Data Gaps on the Poverty and Social Welfare Fronts (Survey of Income and Program Participation Working Paper No. 8705), US Bureau of the Census, Washington, DC.

Schatz, B.R. (1987), "Telesophy: a system for manipulating the knowledge of a community" , Proceedings of the IEEE Globecom '87, Tokyo, November, Computer Society Press of the IEEE, pp. 1181-6.

Schatz, B.R. (1992), "Building an electronic community system" , Journal of Management Information Systems, Vol. 8 No. 3, pp. 87-107.

Scheuermann, P., Yu, C. and Program Committee (1989), Heterogeneous Database Systems, Report of the NSF Workshop on Heterogeneous Database Systems, December 11-13, Department of Computer Science, Northwestern University, Evanston, IL.

Science (1994a), "Science careers: playing to win", (1994). Science, Vol. 265, September 23, pp. 1905-39.

Science (1994b), "Crème de la crème (cont'd)", Science, Vol. 266, December 16, p. 1811.

Silberschatz, A., Stonebraker, M . and Ullman, J.D. (Eds) (1990), Database systems: A chievements and Opportunities, The "Lagunita" Report of the NSF Invitational Workshop on the Future of Database Systems Research, February 22-23, Palo Alto, CA (TR-90-22), Department of Computer Sciences, University of Texas at Austin, Austin, TX.

Simon, H.A. (1991), "Bounded rationality and organizational learning". Organization Science, Vol. 2 No. 1, pp. 125-34. 
Small, H. (1990), Bibliometrics of Basic Research, prepared under contract to the Office of Technology Assessment, (PB 91-166 579), Department of Commerce, National Technical Information Service, Springfield, VA, July.

Steele, G. (1984), COMMON LISP: The Language, Digital Press, Bedford, MA.

US Congress (Office of Technology Assessment) (1986), Research Funding as an Investment: Can We M easure the Returns? - A Technical Memorandum (OTA-TMSET-36), US Congress, Office of Technology Assessment, Washington, DC, April.

US Congress (Office of Technology Assessment) (1988), M apping our Genes - The Genome Projects: How Big, How Fast? (OTA-BA-373), US Government Printing Office, Washington, DC, April.

US Congress (102nd Congress) (1991a), High Performance Computing Act of 1991, Public Law 102-194, 105, Stat, December 9, pp. 1594.

US Congress (Office of Technology Assessment) (1991b), Federally Funded Research: Decisions for a Decade, (OTA-SET-490), US Government Printing Office, Washington, DC, May.
US National Institutes of Health (Office of Science Policy and Regulation) (1993), Staffing Patterns of the National Institutes of Health Research Grants, US Department of Health and Human Services, National Institutes of Health, Washington, DC, March.

Wells, J. (1991), "Processing and analyzing large files with small computers: new technology developments", 1990 Proceedings of the Section on Survey Research Methods, American Statistical Association, Arlington, VA, pp. 121-6.

Wiederhold, G. (1992), "M ediators in the architecture of future information systems", Computer, Vol. 25 No. 3, pp. 38-48.

Wulf, W.A. (1989), "The national collaboratory - a white paper", in "Towards a national collaboratory (appendix A", unpublished report of a National Science Foundation invitational workshop held at Rockefeller University, New York, 17-18 March 1989 (Lederberg, J. and Uncapher, K., co-chairs).

Wulf, W.A. (1993), "The collaboratory opportunity", Science, Vol. 261, August 13, pp. 855-6. 